\title{
Sweeping the chimney before kindling the fire as a workable option for employment policy
}

Citation for published version (APA):

van Zon, A. H., Muysken, J., \& Meijers, H. H. M. (1998). Sweeping the chimney before kindling the fire as a workable option for employment policy. MERIT, Maastricht Economic Research Institute on Innovation and Technology. MERIT Research Memoranda No. 013 https://doi.org/10.26481/umamer.1998013

Document status and date:

Published: 01/01/1998

DOI:

10.26481/umamer.1998013

Document Version:

Publisher's PDF, also known as Version of record

\section{Please check the document version of this publication:}

- A submitted manuscript is the version of the article upon submission and before peer-review. There can be important differences between the submitted version and the official published version of record.

People interested in the research are advised to contact the author for the final version of the publication, or visit the DOI to the publisher's website.

- The final author version and the galley proof are versions of the publication after peer review.

- The final published version features the final layout of the paper including the volume, issue and page numbers.

Link to publication

\footnotetext{
General rights rights.

- You may freely distribute the URL identifying the publication in the public portal. please follow below link for the End User Agreement:

www.umlib.nl/taverne-license

Take down policy

If you believe that this document breaches copyright please contact us at:

repository@maastrichtuniversity.nl

providing details and we will investigate your claim.
}

Copyright and moral rights for the publications made accessible in the public portal are retained by the authors and/or other copyright owners and it is a condition of accessing publications that users recognise and abide by the legal requirements associated with these

- Users may download and print one copy of any publication from the public portal for the purpose of private study or research.

- You may not further distribute the material or use it for any profit-making activity or commercial gain

If the publication is distributed under the terms of Article $25 \mathrm{fa}$ of the Dutch Copyright Act, indicated by the "Taverne" license above, 


\section{MERIT Research Memorandum}

RM 2/98-016

\section{Sweeping the Chimney before Kindling the Fire as a Workable Option for Employment Policy}

by

Adriaan van Zon */+

Huub Meijers*

Joan Muysken */+

Maastricht, May 28, 1998

* MERIT

+ Faculty of Economics and Business Administration, Maastricht University

MERIT, PO Box 616, 6200 MD Maastricht, The Netherlands

tel +31433883890

fax +31433216518

e-mail: adriaan.vanzon@merit.unimaas.nl 


\section{Introduction}

One of the most pressing problems of today is the uneven distribution of the burden of unemployment across different skill groups. Especially low-skilled workers are more often unemployed than other skills (OECD, 1994). They are also unemployed for longer periods of time (Muysken and Ter Weel, 1997). The unevenness of this distribution seems to indicate that having different skills determines to some extent one's employment/unemployment opportunities. However, policy prescriptions meant to alleviate the problems associated with the uneven distribution of unemployment are primarily based on (conceptual) models which effectively ignore skill-differences between workers. Policy recommendations involving wage-flexibility or reductions in costs of hiring and firing, for example, seem to be based on the notion that essentially skills are not the distinctive elements in defining the employment opportunities of an individual. Instead, individual skill-services being over-priced or being too costly to hire and/or fire, are often regarded to be the real cause of disparities in unemployment rates by skill. In this paper we will argue that this neglects the fact that people with high-level skills have intrinsically more employment opportunities than people with low-level skills. This is because low-skilled people may find it (too) hard to fill high-level jobs. ${ }^{1}$ High-skilled people on the other hand may be expected to be able to perform, in principle at least, in both low-level jobs and high-level jobs. In addition, it may well be possible that high-skilled workers are more efficient than low-skilled workers on low-level jobs. Given these asymmetries between low-skilled and high-skilled workers' employment opportunities, it follows directly that the number of low-level jobs is an upper limit to low-skilled employment, while the number of high-skilled jobs is a lower limit to high-skilled employment. ${ }^{2}$ Hence, in the absence of supply bottle-necks, high-skilled employment can not fall below the number of high-level jobs, whereas low-skilled employment may even fall to zero, when high-skilled workers take over low-level jobs. ${ }^{3}$ While, therefore, the creation of a high-level job necessarily favours high-skilled employment, employment prospects of the lowskilled are not necessarily improved by the creation of low-level jobs. The creation of high-level jobs draws high-skilled workers into those jobs, possibly leaving low-level job vacancies in the process. This gives low-skilled workers the opportunity to fill these vacancies. Thus, by 'sweeping the employment chimney' (i.e. the creation of high-level jobs), unemployed lowskilled workers may simultaneously be drawn into the 'employment fire' at the low-skilled end of the chimney. In the Netherlands, this is knwon as the 'chimney effect'. By contrast, an increase in the amount of fuel present at the low end of the chimney through the creation of low-level jobs (this is the trickling down effect mentioned in note 3), may actually result in more smoke rather than a bigger fire. The latter depends to a large extent on the general condition of the employment chimney itself, as we intend to illustrate in this paper.

An additional asymmetry between different skill types of labour lies in the possibility that low-

1) This argument is used by Kettunen (1994) is his job competition model.

2) This is corroborated by the fact that particularly in the lower segment of the labour market over-schooling occurs to a large extent. For the Netherlands this is documented in Goort and Maasen-Van den Brink (1996) and Oosterbeek and Webbink (1996).

3) The implied crowding out effect — or as Dreze and Malinvaud (1993) put it 'trickling down effect' — is not found for the Netherlands by Van Ours and Ridder (1995). However, their results are criticised by both Van der Laan (1996) and De Beer (1996), who do find crowding out effects. 
skilled workers may be low-skilled because it is difficult for them to learn enough to become high-skilled. With firms having become 'leaner and meaner' over the last decade, this 'learninginability' may provide incentives for entrepreneurs to hire workers who are flexible in the sense that they could easily learn different types of tasks, instead of hiring people who can only perform a limited number of tasks. These learning asymmetries between low-skilled and high-skilled workers may also be part of the explanation of the uneven distribution of unemployment across skills. $^{4}$

The above suggests that there are a number of ways to increase the employment prospects of low-skilled workers. The first one is by increasing the number of low-level jobs, the second by decreasing the relative labour costs of low-skilled workers thus increasing the willingness of entrepreneurs to allocate low-skilled workers instead of high-skilled workers to low-level jobs, and the third by increasing the number of jobs which only high-skilled workers can take. A fourth option would be to uplift the skill-level of low-skilled workers to some extent by means of (re-) training programmes. The effectiveness of the first possibility depends in part on the availability of high-skilled workers for low-level jobs. The effectiveness of the second measure is limited to the extent that such a change in relative wage costs at first tends to increase the unemployment of high-skilled workers while decreasing the unemployment of low-skilled workers. However, when wage-costs per unit of output would fall, a net expansion of jobs may be expected to occur and therefore a positive net effect on overall employment. Otherwise the bias in unemployment will just shift against high-skilled workers. ${ }^{5}$ The third measure structurally decreases the availability of high-skilled workers for low-level jobs, and hence increases employment prospects for the low-skilled, almost as a beneficial side-effect. The fourth measure, in as far as it would be feasible, would be highly desirable, for it would structurally diminish the constraints put on employment opportunities by the existence of substitution asymmetries between skills.

In this paper we will describe a model which combines most of the notions regarding asymmetries in employment perspectives between low-skilled workers and high-skilled workers mentioned above. We will look at the influence of asymmetries in substitution possibilities between skills, but also of asymmetries in learning capabilities between skills. To this end we specify a model of labour demand defined in terms of jobs, which, given the supply of labour which is heterogeneous in the skill-dimension, requires matches to be made between the skills supplied and the jobs under consideration. The model is highly neo-classical in nature except for the asymmetries mentioned above. The skill allocation model to be described in this paper is part of a more general production structure which has an explicit vintage production structure (see MASTER (1997) for more details). In this paper, however, we focus exclusively on the skill allocation model and the way in which it allows the chimney effect to do its work.

The set-up of this paper is as follows. In section 2 we describe the principle outlines of the skill allocation model called SAM. It summarises the more detailed model description present in

4) Gelderblom cs. (1997) observe that education may be related to the opportunity to find a job, which in turn may lead to crowding out of low-skilled persons.

5) Note, however, that differences in relative efficiencies of different skills in a certain job, may actually lead to net changes in unemployment measured in man-years, while employment measured in efficiency units could remain the same. We will come back to this later. 
MASTER (1997). Section 3 describes the results we have obtained with a first empirical implementation of the skill allocation model for Germany and the Netherlands. Section 4 describes the outcomes of two ex post simulation experiments conducted for those countries. These experiments were performed in order to highlight the differences between the working of the chimney effect and standard policy methods to favour employment prospects of low-skilled workers. Section 5 contains a summary and some concluding remarks.

\section{A Model of Substitution Asymmetries between Jobs and Skills}

\section{Introduction}

High-skilled people may in general be expected to perform better in low-level jobs than lowskilled people in high-level jobs. Hence there is an intrinsic bias against allocating low-skilled people to high-level jobs. Nonetheless, some kind of substitution between higher skills and lower skills should be possible (in principle at least), since there is empirical evidence to this effect. ${ }^{6}$ Our approach differs from the foregoing approaches in that we distinguish between substitution possibilities between jobs as well as between skills, because these are intrinsically different. In our set-up, a job is a set of tasks which need to be performed. This requires the people engaged in that job to have a certain minimum skill-level in order to be able to perform the tasks in question. These specific minimum skill requirements define the level of the job. Therefore, generally speaking, high-skilled people can be hired for more job-levels than low-skilled people. This provides an asymmetry in employment opportunities for high-skilled and low-skilled people, which, given a certain lack of compensating asymmetries in wage formation, leads to a bias in employment opportunities in favour of high-skilled people.

\section{Ex Ante Job Demand and Ex Post Skill Demand}

We assume that the design of a production process entails the definition of certain packages of tasks for low- and high-skilled people. We assume furthermore that technical constraints on combining these tasks are such that a decrease of the number of high-level jobs must be compensated by an increase in the number of low-level jobs and vice versa. ${ }^{7}$ But, once a jobcombination has been chosen and implemented in the design of machinery and equipment, it can not be altered : the job-composition of employment is assumed to be 'putty' ex ante and 'clay' ex post. We also assume that the capital stock depreciates with rate $\delta$, and so does the number of jobs embodied in the capital stock. We furthermore assume that the efficiency of a high-skilled worker on a low-level job relative to the efficiency of a low-skilled worker on that job is given by the constant number e'. This implies that e' low-skilled workers on a low-level job could be

6) Many writers have investigated the possibility of direct substitution between skill-categories. A survey for the US is provided by Hamermesh and Grant (1979), while Hebbink (1990) and Broer and Jansen (1989) provide some results for the Netherlands. Kugler c.s. (1990) do the same for Germany. Mincer (1989) provides additional results for the US. The general conclusions which emerge from these studies are first that capital and high-skilled labour are complements, while secondly low-skilled labour and the capital/high-skilled labour complex are substitutes.

7) These are the 'standard' substitution assumptions in neo-classical production theory. We also assume that the implied 'job aggregator function' or 'job substitution function' obeys the usual restrictions on the signs of the first and second partial derivatives. 
replaced by one high-skilled worker : we assume therefore that the actual allocation of skills to jobs is essentially 'putty' ex post. ${ }^{8}$ The corresponding substitution possibilities between highand low-skilled workers on a low-level job are given by equation (2.1), which combines the substitution and relative efficiency assumptions mentioned above:

$$
L_{t}=L^{*} \cdot e^{-\delta t}-e^{\prime} \cdot\left(H_{t}-H^{*} \cdot e^{-\delta t}\right)
$$

The framework sketched above can be pictured as in Figure 1. In this figure, $\mathrm{H}^{*}$ and $\mathrm{L}^{*}$ denote high-level and low-level jobs, respectively, while $\mathrm{H}$ and $\mathrm{L}$ denote high- and low-skilled workers, respectively. Ex ante job-combinations $\left(\mathrm{H}^{*}, \mathrm{~L}^{*}\right)$ are described using a standard 'unit job-isoquant', while the feasible ex post combinations of high- and low-skilled workers associated with a certain job-combination are given by linear relations in the L,H quadrant as described by (2.1).

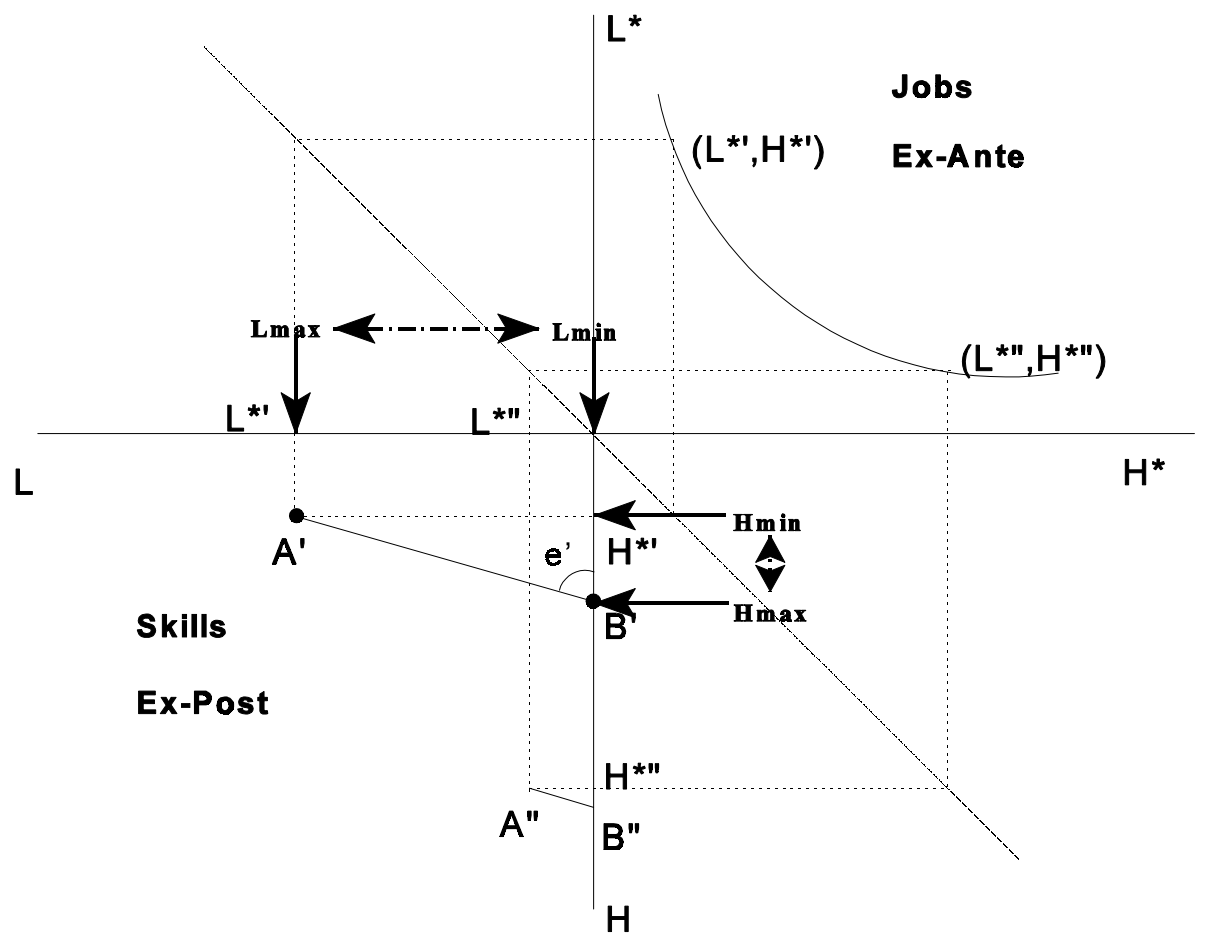

Figure 1 Ex-ante job substitution and ex-post skill substitution

In Figure 1, job combinations $\left(\mathrm{L}^{*}, \mathrm{H}^{*}\right)$ are given in the Nort-East quadrant. The 45-degree lines in the North-West and South-East quadrants are used to obtain the skill-substitution possibilities between $\mathrm{L}$ and $\mathrm{H}$ for any given job-combination $\left(\mathrm{L}^{*}, \mathrm{H}^{*}\right)$ as depicted in the South-West quadrant. Note that in the latter quadrant, the lines through the points A',B' and the points A",B" are parallel lines. The angle of these lines with respect to the horizontal is equal to -1/e' (see equation (2.1)). The ex-ante choice on the job-combination determines the minimum and maximum

8) We are referring here to substitution possibilities between low-skilled and high-skilled workers on lowlevel jobs only, since, by assumption, high-level jobs can only be taken by high-skilled workers. 
employment opportunities for both low- and high-skilled workers. For instance, in the case of the job-combination ( $\mathrm{L}^{*}, \mathrm{H}^{*}$ ), low-skilled employment is bounded between Lmin and Lmax whereas high-skilled employment is bounded between Hmin and Hmax. Note furthermore from this figure, that the line A"B" represents smaller employment opportunities for low-skilled workers than the line A'B' due to the fact that the number of low-level jobs in job-combination $\left(\mathrm{L}^{*}, \mathrm{H}^{*}\right.$ ') is much smaller than in job-combination $\left(\mathrm{L}^{*}, \mathrm{H}^{*}\right.$ '). Note, that the intercepts $\mathrm{B}^{\prime}$ and B" represent the maximum number of high-skilled workers associated with a certain jobcombination, i.e. B' and B" are the number of high-skilled workers fully occupying both lowlevel and high-level jobs. From now on we define this maximum number of high-skilled workers to be $\mathrm{H}^{\prime}$. Finally, it should be noted that the choice of a certain point in the $\mathrm{L}^{*}, \mathrm{H}^{*}$-quadrant, defines a feasible choice-set in the L,H-quadrant as given by (2.1).

Assuming that entrepreneurs can determine the job-layout of their production process (i.e. $\left.\left(\mathrm{H}^{*}, \mathrm{~L}^{*}\right)\right)$ only when new capacity is installed, it follows that the expected present value of the operating cost of one labour-efficiency unit installed at time zero declines over time with the discount rate $r$ and with the rate of technical depreciation $\delta .{ }^{9}$ Hence, the expected present value of total operating cost of one labour-efficiency unit which is installed at time zero is given by:

$$
T=\int_{0}^{\infty}\left(w_{H, t}^{e} \cdot H_{t}+w_{L, t}^{e} \cdot L_{t}\right) \cdot e^{-r \cdot t} d t
$$

where $\mathrm{w}_{\mathrm{H}, \mathrm{t}}^{\mathrm{e}}$ and $\mathrm{w}_{\mathrm{L}, \mathrm{t}}^{\mathrm{e}}$ are the expected values of the wage rate for high-skilled and for low-skilled workers at time $\mathrm{t}$.

\section{The Allocation of Skills in the Absence of Skill Supply Constraints and Adjustment Costs}

In the absence of supply constraints and adjustment costs, and given a job-combination $\left(\mathrm{L}^{*}, \mathrm{H}^{*}\right)$, the choices of $\mathrm{L}_{\mathrm{t}}$ and $\mathrm{H}_{\mathrm{t}}$ can be modelled by solving:

$$
\begin{aligned}
\operatorname{Min} F_{t} & =\int_{0}^{\infty}\left(w_{H, t}^{e} \cdot H_{t}+w_{L, t}^{e} \cdot L_{t}\right) \cdot e^{-r \cdot t} \\
\text { s.t. } L_{t} & =L^{*} e^{-\delta \cdot t}-e^{\prime} \cdot\left(H_{t}-H^{*} e^{-\delta \cdot t}\right)
\end{aligned}
$$

Given the linear nature of the problem, $\left(\mathrm{H}=\mathrm{H}^{\prime}, \mathrm{L}=0\right)$ is the solution to $(2.3)$ when $\mathrm{w}_{\mathrm{H}}^{\mathrm{e}} / \mathrm{w}_{\mathrm{L}}^{\mathrm{e}}<\mathrm{e}^{\prime}$, while $\left(L=L^{*} e^{-\delta \cdot t}, H=H^{*} e^{-\delta \cdot t}\right)$ is the solution when the opposite is the case. ${ }^{10}$ Using the shorthand notation $\mathrm{w}=\mathrm{w}_{\mathrm{H}}^{\mathrm{e}} / \mathrm{w}_{\mathrm{L}}^{\mathrm{e}}$ and $\hat{\mathrm{w}}=\hat{\mathrm{w}}_{H}-\hat{\mathrm{w}}_{L}$, for given and constant expected exponential growth rates $\hat{w}_{H}$ and $\hat{w}_{L}$, there are now four distinct possibilities to consider, depending on whether $\mathrm{w}<\mathrm{e}^{\prime}$ or $\mathrm{w}>\mathrm{e}^{\prime}$ and $\hat{w}<0$ or $\hat{w}>0$. For instance, when $\mathrm{w}<\mathrm{e}^{\prime}$ and $\hat{w}<0$ (case 1$)$ the

9) The influence of $\delta$ is already accounted for in the definition of $\mathrm{L}$ and $\mathrm{H}$ in terms of $\mathrm{L}^{*}$ and $\mathrm{H}^{*}$ (see equation (2.1)).

10) From now on we drop time-subscripts, unless this would lead to confusion.

$$
-5-
$$


optimal solution will always be $\left(\mathrm{H}=\mathrm{H}^{\prime}, \mathrm{L}=0\right)$. But when $\mathrm{w}\left\langle\mathrm{e}^{\prime}\right.$ and $\hat{w}>0$ (case 2) there will be a moment when the other solution $\left(\mathrm{H}=\mathrm{H}^{*}, \mathrm{~L}=\mathrm{L}^{*}\right)$ will be chosen. A switch between states will also occur in case 3 , which starts out with $\mathrm{w}>\mathrm{e}^{\prime}$ and $\hat{w}<0$. Case 4 will always have $\left(\mathrm{H}=\mathrm{H}^{*}, \mathrm{~L}=\mathrm{L}^{*}\right)$ since $w>e^{\prime}$ and $\hat{w}>0$. The four cases are depicted in Figure 2.

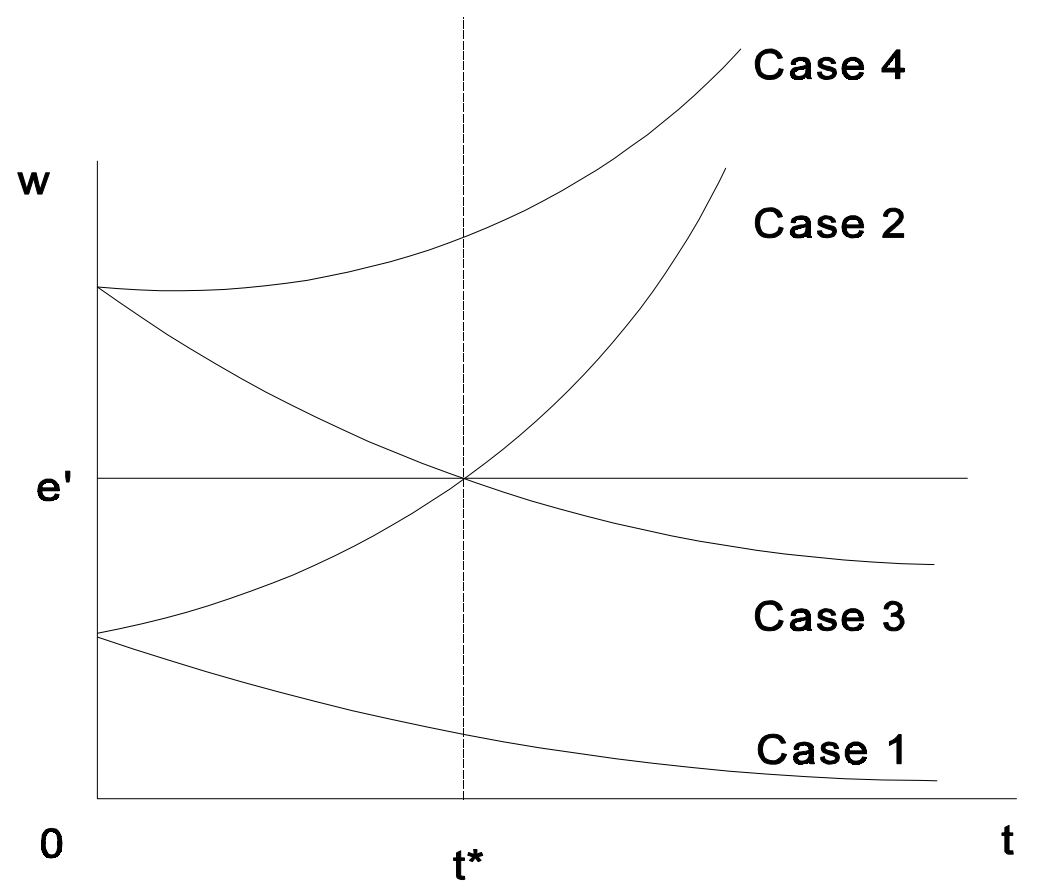

Figure 2 Expected Wage Growth and Skill-Switching

In cases 2 and 3 a switch from the one corner solution of (2.3) to the other will take place at time $t^{*} .{ }^{11} t^{*}$ itself is easily determined from the condition that at the moment of switching:

$$
w_{t^{*}}=\frac{w_{H, t^{*}}}{w_{L, t^{*}}}=\frac{w_{H, 0}}{w_{L, 0}} \cdot e^{\left(\hat{w}_{H}-\hat{w}_{L}\right) \cdot t^{*}}=e^{\prime} \Rightarrow t^{*}=\frac{\ln \left(e^{\prime} /\left\{\frac{w_{H, 0}}{w_{L, 0}}\right\}\right)}{\hat{w}_{H}-\hat{w}_{L}}
$$

Using equation (2.4), the solution of the original problem over an infinite horizon can be defined as the solution to the problem of minimizing unit operating costs over two consecutive horizons, namely $0-t^{*}$ and $t^{*}-\infty$. Thus, the minimum expected present value of operating costs of a lowlevel job can be obtained directly for all four cases.

11) Although this has not been indicated in Figure 2, $t^{*}$ can of course be different for cases 2 and 3. 


\section{Choosing Jobs}

The solution to the allocation problem defined by the minimisation of (2.3) subject to (2.1), is easily obtained by substituting (2.1) and (2.4) into (2.3). The solution of the objective function for case 1 can now be written as:

$$
T_{1}=\int_{0}^{\infty} w_{H, 0} \cdot H^{\prime} \cdot e^{\left(\hat{w}_{H}-\rho\right) \cdot t} d t=-\frac{w_{H, 0}}{\hat{w}_{H}-\rho} \cdot\left(L^{*} / e^{\prime}+H^{*}\right)=\alpha_{1} \cdot H^{*}+\beta_{1}
$$

where $\alpha_{1}$ and $\beta_{1}$ are implicitly defined by (2.5), and $\mathrm{T}_{1}$ denotes the value of the objective function given by (2.3) for case 1 as depicted in Figure 2. The term $\rho$ is equal to the rate of technical decay plus the discount rate. Note that $\alpha_{1}, \beta_{1}>0$. Note also that the objective function $\mathrm{T} 1$ is linear in $\mathrm{L}^{*}$ and $\mathrm{H}^{*}$. Hence, maximisation of $\mathrm{T} 1$ by choosing $\left(\mathrm{L}^{*}, \mathrm{H}^{*}\right)$ constrained by the unit job-isoquant implicitly defined by $\phi\left(\mathrm{L}^{*}, \mathrm{H}^{*}\right)=1$, provides values for $\mathrm{L}^{*}$, and $\mathrm{H}^{*}$ in terms of $\mathrm{e}^{\prime}$, relative wages, relative growth rates in wages and the parameters of the job-substitution function $\phi\left(\mathrm{L}^{*}, \mathrm{H}^{*}\right)$. As was the case with $\mathrm{T}_{1}, \mathrm{~T}_{2}-\mathrm{T}_{4}$ can also be written as $T_{i}=\alpha_{i} \cdot H^{*}+\beta_{i} \cdot L^{*} \cdot{ }^{12}$ The $\alpha$ 's and $\beta$ 's can readily be interpreted as the expected present value of the minimum cost of operating high- and low-level jobs conditional on expectations with regard to the growth of relative wages. The solution to the job-composition problem is therefore implicitly given by the standard first order condition for a cost-minimisation problem:

$$
\left(\frac{\partial \phi}{\partial H_{k}^{*}}\right) /\left(\frac{\partial \phi}{\partial L_{k}^{*}}\right)=\frac{\alpha_{k}}{\beta_{k}}
$$

where $\mathrm{L}^{*}{ }_{\mathrm{k}}$ and $\mathrm{H}^{*}{ }_{\mathrm{k}}$ reflect the optimum values of $\mathrm{L}^{*}$ and $\mathrm{H}^{*}$ when case $\mathrm{k}$ (for $\mathrm{k}=1-4$ as depicted in Figure 2) is expected to hold. Note that (2.6) is totally comparable with the first order conditions of a static cost-minimisation problem, and hence we can conclude that a fall in the ratio $\alpha_{k} / \beta_{k}$ corresponds to a rise in the relative expected present value of the operating cost of a low-level job. This in turn leads to a decrease in the slope of the iso-cost lines and hence to a movement down the unit job isoquant (see Figure 1) and therefore to a decrease in the $\mathrm{L}^{*} / \mathrm{H}^{*}$ ratio.

The optimum choice of a job-combination as described above, can easily be understood by 'folding' Figure 1 along the 45-degree line in the North-WEest and South-East quadrants, so that the job-dimension and the skill-dimension in Figure 1 would come to overlap completely. The result of this 'folding' is depicted in Figure 3. 


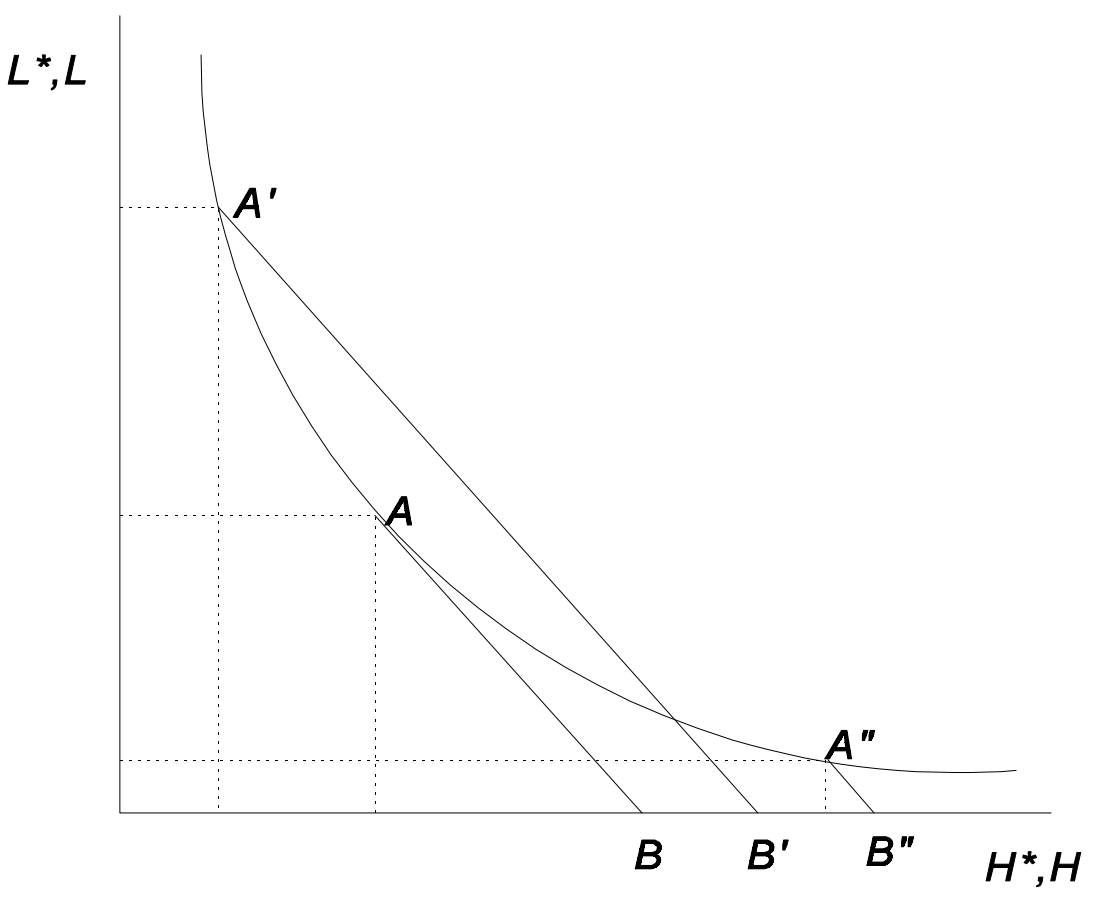

Figure 3 Ex Ante Job Choices

In this figure the points A',A",B' and B" correspond with the same points in Figure 1. The lines through A'B' and through A"B" now both have slope -e', however. The vertical and horizontal axes measure two dimensions at the same time. Points on the straight lines with slope -e' are points in the $\mathrm{L}, \mathrm{H}$ dimension, while job-combinations on the unit job-isoquant through points $\mathrm{A}^{\prime}, \mathrm{A}, \mathrm{A}$ " are actually points in the $\mathrm{L}^{*}, \mathrm{H}^{*}$ dimension. Point $\mathrm{A}$ on the unit job-isoquant has slope -e' by construction.

It is fairly easy to show from the parameterisation of the $\alpha / \beta$ ratios (see MASTER (1997)) that case 1 will have the lowest value of the $\mathrm{L}^{*} / \mathrm{H}^{*}$ ratio, while case 3 will have a larger $\mathrm{L}^{*} / \mathrm{H}^{*}$ ratio than case 4. Case 2 in turn will have a larger $\mathrm{L}^{*} / \mathrm{H}^{*}$ ratio than case 1, that is: $\left(\mathrm{L}^{*} / \mathrm{H}^{*}\right)_{3}>\left(\mathrm{L}^{*} / \mathrm{H}^{*}\right)_{4}$ $>\left(\mathrm{L}^{*} / \mathrm{H}^{*}\right)_{1}=\mathrm{e}^{\prime}$ and $\left(\mathrm{L}^{*} / \mathrm{H}^{*}\right)_{2}>\left(\mathrm{L}^{*} / \mathrm{H}^{*}\right)_{1}=\mathrm{e}^{\prime}$. Case 1 is especially interesting, since the corresponding $\mathrm{L}^{*} / \mathrm{H}^{*}$ ratio depends on $\mathrm{e}^{\prime}$ only. This is caused by the fact that e' provides a limit to the marginal rate of substitution of high-level jobs for low-level jobs which is determined by economic considerations. Indeed, it does not pay to let the marginal rate of job-substitution along the unit job-isoquant fall below e', because the corresponding solution to the cost-minimisation problem $\left(\mathrm{L}=0, \mathrm{H}=\mathrm{H}^{\prime}\right)$ would in that case result in an increase in the operating cost of a low-level job. This follows immediately from Figure 3, where a job-combination to the right of point A on the unit job-isoquant obviously generates a corresponding point on the horizontal axis to the right of point $\mathrm{B}$. Because in this case the solution to the cost-minimisation problem would be ( $\mathrm{L}=0, \mathrm{H}=\mathrm{H}^{\prime}$ ), it follows that any point on the horizontal to the right of $\mathrm{B}$ represents higher total expected wage-costs than point $B$ itself. Hence, from a cost-minimisation point of view, any point to the right of $\mathrm{B}$ is inferior to $\mathrm{B}$ itself. The same conclusion obviously applies to points on the unit job-isoquant to the right of point A. For a more detailed discussion of these results, see MASTER (1997). 


\section{The Allocation of Skills and Learning Asymmetries}

We now assume that the allocation of a specific skill to a job gives rise to adjustment costs, which we link to learning cost. When a person is allocated to a job, we assume that he needs to spend some time learning all the tricks in the trade. The time spent is a given fraction of 'normal working hours' for a person of a similar skill-level already trained for the job. We assume furthermore that a trainee doesn't produce anything while learning. Nonetheless the trainee gets paid for his time. This implies that the learning cost per person is proportional to the wage rate which applies to the skill-level of the person in question. The corresponding factor of proportion depends both on the skill-level of the person in question and the type of job this person is trained for. In addition to this, we assume that each time a job is filled, training costs will have to be incurred. Obviously, people who have been trained already for a certain job do not have to be trained again as long as they remain allocated to the job they have been trained for. Consequently, the experience they have in a certain job brings about an additional asymmetry in the costs of operating a job by either experienced workers or inexperienced workers of the same skill type.

Let the training cost of an allocation of skill $i$ to jobtype $j$, as a fraction of the relevant wage rate $\mathrm{W}_{\mathrm{i}}$, be represented by the symbol $\xi_{\mathrm{i}, \mathrm{j}}$. Furthermore, let us consider the case where $\hat{w}>0$. Then, eventually the allocation ( $\left.\mathrm{L}->\mathrm{L}^{*}\right)$ will be the cost-minimising allocation, because the relative wage rate of high-skilled workers will become infinitely high, while the relative efficiency e' of high-skilled workers vis a vis low-skilled workers in low-level jobs will remain the same. The question arises whether low-skilled workers (L) should be allocated to a low-level job ( $\mathrm{L}^{*}$ ) from the outset, or high-skilled workers $(\mathrm{H})$ should be allocated to that low-level job first. As in the no-adjustment case, we assume that this depends on the present value of operating the job over an infinite period of time for given expectations of the growth rate of relative wages and for given values of the learning cost parameters.

For experienced workers initial matching costs can be disregarded. However, for a switch in the future, we assume that entrepreneurs will always expect to use inexperienced workers, in order to be on the 'safe side'. Hence, the present value of the cost of 'manning' and operating a lowlevel job by starting with the allocation $\left(\mathrm{H}->\mathrm{L}^{*}\right)$ first and then switching to the final allocation $\left(\mathrm{L}->\mathrm{L}^{*}\right)$ at time $\mathrm{t}^{*}$ can be written as a function of $t^{*}$ and the various expected present values of the wage costs associated with the different skills to be allocated to the low-level job. As we show in MASTER (1997), this relation can be used to obtain the optimum switching time $t^{*}$ for an allocation sequence which starts out with the allocation (H->L*) and which ends with the allocation (L-> $\left.\mathrm{L}^{*}\right)$ by minimisation of the expected costs w.r.t. $\mathrm{t}^{*}$, giving :

$$
t^{*}=\frac{\ln \left(\left\{\frac{e^{\prime}}{w_{0}}\right\} \cdot\left\{1+\left(\rho-\hat{w}_{L}\right) \cdot \xi_{L, L^{*}}\right\}\right)}{\hat{w}}
$$

$t^{*}$ depends positively on the (effective) rate of discount $\rho$ (which includes the rate of technical 
decay). ${ }^{13}$ A rise in either of the parameters would decrease the relative importance of future costs in the present value of total cost per low-level job. Hence, the incentive to switch would diminish, thus increasing $t^{*}$, ceteris paribus. Likewise, a rise in the adjustment cost of the final allocation (L-> $\mathrm{L}^{*}$ ) would tend to postpone the moment of switching, i.e. increase $t^{*}$, while a rise in the rate of growth of the wage rate of the skill used in the final allocation, would tend to increase the unit cost associated with that allocation, and hence the moment of switching may again be expected to be postponed. This is in line with the fact that $\frac{\partial t^{*}}{\partial \hat{w}_{L}}>0$, for $t^{*}>0$. Note that the introduction of switching costs postpones the moment of switching (c.f. equation (2.4)).

From equation (2.7) it is clear that $\mathrm{t}^{*}$ is positive, only when $w_{0}<e^{\prime} \cdot\left(1+\left(\rho-\hat{w}_{L}\right) \cdot \xi_{L, L^{*}}\right)$, since

$\hat{w}>0$ by assumption. If $t^{*}$ is positive, then an entrepreneur who had started out with the allocation $\left(\mathrm{H}-\mathrm{L}^{*}\right)$ would be happy to stick with that allocation upto time $\mathrm{t}^{*}$. If $w_{0}>e^{\prime} \cdot\left(1+\left(\rho-\hat{w}_{L}\right) \cdot \xi_{L, L^{*}}\right), \mathrm{t}^{*}$ would be negative, and the optimum moment of switching from

$\left(\mathrm{H}->\mathrm{L}^{*}\right)$ to $\left(\mathrm{L}->\mathrm{L}^{*}\right)$ would lie in the past, implying that under the circumstances it would have been wise to choose the final allocation ( $L->L^{*}$ ) from the outset. But even if $t^{*}>0$, it may be wise to start with the allocation $\left(\mathrm{L}->\mathrm{L}^{*}\right)$ rather than the allocation $\left(\mathrm{H}->\mathrm{L}^{*}\right)$, for minimisation of the expected present value of operating costs with respect to $t^{*}$ really assumes that learning costs associated with the allocation $\left(\mathrm{H}->\mathrm{L}^{*}\right)$ have already been sunk. This would obviously be true in the case of experienced workers, but false in case of inexperienced workers. In order to resolve this issue, a direct comparison must be made between the expected operating costs associated with both feasible allocation sequences (L->L*,L->L*) and (H->L*,L->L*).

The analysis above can be repeated for the case where $\hat{w}<0$, which implies that ultimately the allocation $\left(\mathrm{H}->\mathrm{L}^{*}\right)$ instead of $\left(\mathrm{L}->\mathrm{L}^{*}\right)$ will be the least costly one. The analysis is completely analogous to the one above, and it is therefore not repeated here.

\section{Linear Programming and the 'Chimney Effect'}

In order for the chimney effect to work, it is necessary to introduce supply constraints which take account of asymmetries in substitution possibillities between high- and low-skilled workers. In those circumstances, an increase in the number of high-level jobs would require an increase in the employment of high-skilled workers on those jobs. The inflow of high-skilled workers into those high-level jobs would in part have to be met by an outflow of high-skilled workers from low-level jobs. The employment-holes this outflow would leave in low-level jobs, creates the

13) In van Zon and Muysken (1996), switching costs are introduced by means of the notion of a switching threshold $\Delta$. I.e. entrepreneurs switch from $\left(\mathrm{H}->\mathrm{L}^{*}\right)$ to $\left(\mathrm{L}->\mathrm{L}^{*}\right)$ only when $\mathrm{w}>\mathrm{e}^{\prime}(1+\Delta)$ and $\hat{w}>0$. Note that $\Delta$ can directly be interpreted in terms of matching costs, since the switching threshold approach and the matching costs approach taken here are equivalent when $\Delta=\left(\rho-\hat{w}_{L}\right) \cdot \xi_{L, L}$. 
employment-opportunities on which the low-skilled workers ultimately depend. In order to add supply constraints to the existing labour demand framework, we can use the technique of Linear Programming, as we have done before in van Zon and Muysken (1992). In this way, we are able to account explicitly for both job-demand constraints and skill-supply constraints.

\section{Definition of the Linear Programming Problem}

The demand side described so far ignores supply constraints. Consequently, the allocation of skills to jobs referred to first best allocations only. But explicit supply constraints which become binding may force entrepreneurs to use second best allocations instead. In order to be able to cover both first-best and second-best allocations, we assume that entrepreneurs solve a linear programming problem in which they try to meet job requirements as well as skill supply constraints, while minimising the mismatch ${ }^{14}$ between skill-levels and job-levels on low-level jobs.

The definition of the linear programming problem is now quite straightforward. Let $\mathrm{E}_{\mathrm{j}, \mathrm{k}}^{\mathrm{i}}$ denote the employment of skill $\mathrm{j}$ with experience type $\mathrm{i}$ on job $\mathrm{k}$. The index $\mathrm{i}$ has two values : experienced and inexperienced with respect to the match in question. The distinction between experienced and inexperienced workers is important because of the fact that the allocation of an inexperienced worker with a certain skill level implies having to bear the training/matching costs associated with that particular combination of skills and jobs, while this is not the case with experienced workers. Consequently, it is important to distinguish between experienced and inexperienced workers at the supply side too. In this respect we simply assume that the experienced workers available for allocation in the present period are those which were allocated to the job under consideration in the previous period, adjusted for a constant exit-rate. Supply from other sources (like the educational system or the unemployment pool), which is available for employment is inexperienced by assumption.

Given these supply constraints, we can now force the solution of the linear programming problem to be as close as possible to the first-best allocation sequence in the following way. First we introduce the notion of the quasi-job-utilisation rate $\mathrm{q}$ with $0<=\mathrm{q}<=1$ ). When $\mathrm{q}=1$, the skills allocated to low-level jobs and high-level jobs are exactly sufficient to generate the labour efficiency units in those jobs as implied by the composition and level of labour demand by job. At the same time, consistency between ex ante and ex post considerations would require a particular allocation of a skill to a certain job to be the one which follows from the ex ante costconsiderations, unless supply constraints for the skill in question prove to be binding. Hence, the assignment of skills to jobs at any moment in time can be seen as the implementation of the first parts of the various allocation sequences associated with the different jobs under consideration,

14) Note that the term mismatch used here, usually refers to the a priori notion that the best match is the one where the skill-level is exactly equal to the job-level. From a (learning) cost-minimisation point of view, this is not necessarily the case, because of the possibility of 'skill-switching'. In this context therefore, a mismatch refers to a non cost-minimising allocation of skills to jobs, which is due to the existence of supply constraints. 
within the constraints set by the supply of the various skills involved. ${ }^{15}$

Let $\mathrm{J}^{*}{ }_{\mathrm{k}}$ denote the optimum job-levels $\mathrm{H}^{*}, \mathrm{~L}^{*}$ where $\mathrm{k}$ denotes a job-level), i.e. the number of people with a corresponding skill-level needed to fill the job. Let $\mathrm{P}_{\mathrm{j}, \mathrm{k}}^{\mathrm{i}}$ denote the wage-cost (including the corresponding training cost for inexperienced workers) associated with a non-zero value of first- and/or second best allocation sequences starting with the employment of skill $j$ and experience type $\mathrm{i}$ on type $\mathrm{k}$ jobs. $\mathrm{V}$ denotes the total labour costs associated with the allocation sequence which results in maximum costs. ${ }^{16}$ Then, the following linear programming problem can be defined:

$$
\begin{array}{rlrl}
\operatorname{MAX} F & =q \cdot V-\sum_{j} \sum_{k} \sum_{i} P_{j, k}^{i} \cdot E_{j, k}^{i} \\
\text { s.t. } \sum_{i} \sum_{j} e_{j, k} E_{j, k}^{i} & \geq q \cdot J_{k}^{*} \quad \forall k \\
E_{j, k}^{x} & \leq S_{j, k}^{x} \quad \forall j, k \\
\sum_{i} \sum_{k} E_{j, k}^{i} & \leq S_{j} & \forall j \\
q & \leq 1
\end{array}
$$

where $S_{j}$ denotes the total supply of skill $j$ at time $t, S_{j, k}^{i}$ is the total supply of skill $j$ with experience type $i$ with respect to job $k$. $e_{i, j}^{\prime}$ is the relative efficiency of skill-level $i$ on job-level $\mathrm{j}$. Note that $\mathrm{e}_{\mathrm{j}, \mathrm{k}}^{\prime}=0$ for skill-levels $\mathrm{j}$ less than the job-level $\mathrm{k}$, and $\mathrm{e}_{\mathrm{j}, \mathrm{j}}^{\prime}=1$ for all $\mathrm{j}$, by definition.

The first constraints are the job demand constraints. The employment of available skills should generate the required efficiency units of labour in each job. The second set of constraints is the set of skill supply constraints. These constraints state that the total use of experienced workers can not exceed the available supply. The third set of constraints states that the total use of skills may not exceed total supply including both experienced and inexperienced workers. The last constraint in combination with the first, requires employment to be not larger than needed. From (2.8) it follows that maximisation of $F$ requires both $q$ to be equal to 1 and a cost-minimising allocation sequence to be chosen, as it should.

Given the solution to this LP-problem, total employment by skill can now readily be obtained by aggregating over all experience categories and all jobs. The only things which need to be defined are the expected present value of the costs of the relevant allocation sequences per unit of the

15) Note that because the linear programming problem is essentially a static optimisation problem, the intertemporal effects of particular allocations are not taken into account (like, for instance, the fact that the inexperienced workers of today are the experienced workers of tomorrow). In the case of intertemporal optimisation under uncertainty regarding the level of demand for output, other interesting aspects of asymmetries in learning costs and substitution possibilities by skill become more relevant. In particular, one can envisage a situation where a bias would be expected in the demand for skills towards the ones which could be used in as many jobs as possible at intertemporal costs which are as low as possible (including expected matching costs). This provides an intertemporal cost minimisation interpretation to the notion of a 'flexible' worker.

16) V therefore represents the operating cost of the worst case allocation sequence. 
skill which is the first one in each sequence, i.e. the $\mathrm{P}_{\mathrm{j}, \mathrm{k}}^{\mathrm{i}}{ }^{\prime} \mathrm{s}$.

\section{The Valuation of Alternative Allocation Sequences}

In valueing a certain allocation sequence, we assume that entrepreneurs do not expect to face supply constraints in the future, unless they are faced with supply constraints in the present. But even if the latter is the case, they are assumed to act as if these supply constraints would remain binding for $\Theta$ years only. Non-binding supply constraints are assumed to remain non-binding forever, until proven wrong. Furthermore, future matches/switches, as opposed to present matches, are assumed to involve inexperienced workers in all cases.

Given expectations regarding the growth rate of relative wages by skill, the optimum switching moment $t^{*}$ for each possible allocation sequence starting with a certain skill can be calculated. If $t^{*}$ proves to be positive, then the allocation sequence in question may prove to be first-best. If not, then the allocation sequence must be second best, because switching to the second part of the allocation sequence at time zero i.e. starting out with the second part of the allocation sequence, as indicated by $t^{*}<=0$, would lead to a lower expected present value of the costs of the allocation sequence under consideration. Note, however, that this second-best allocation sequence would only be chosen when supply constraints would force entrepreneurs to actually do so. Hence, in this particular case, entrepreneurs expect to stay at least $\Theta$ years with this particular skill-job combination, after which they could decide to return to the unconstrained optimum allocation sequence, if that would prove to be worthwhile, or they could decide to stick with the 'forced' allocation instead. The latter could actually prove to be the most profitable thing to do, since 'returning' to the unconstrained allocation sequence entails the 'sinking' of matching costs in the future. We now assume that the cost to be assigned to the first part of the allocation sequence is equal to the minimum of these two options, i.e. 'sticking' and 'returning'.

When we would evaluate the expected present value of the costs of a certain allocation sequence starting out with an experienced worker, then the corresponding costs of the same allocation sequence starting out with an inexperienced worker can simply be obtained by adding matching costs to the cost of an experienced worker. Hence, all possible matches can be defined knowing the expected present value of allocating an experienced worker to a certain job, as part of a certain allocation sequence. These present value costs of the various allocation sequences are described in more detail in MASTER (1997).

\section{Asymmetries in Matching Behaviour}

One of the problems associated with the linear programming approach taken here is that small changes in relative wages could bring about large changes in the optimum composition of employment. The introduction of a distinction between experienced workers and inexperienced ones 'causes' entrepreneurs to have a tendency to stick to a certain allocation once it has been made in the past for whatever reason (either because it was an optimum allocation in the first place, or a second best allocation due to supply shortages), because learning costs will be sunk in the process. However, it is still possible that large changes in the skill composition of employment occur when wage differentials more than offset learning costs. 
In order therefore to smooth this transition between different skill compositions of employment, we assume, just like van Zon and Muysken (1996) have done, that entrepreneurs differ with respect to the value of their switching thresholds (perceived switching/matching/learning costs in this case). In fact, we assume that the population of entrepreneurs can be subdivided into 'fastswitchers' (characterised by relatively low perceived adjustment costs) and 'slow switchers'. The relative class-sizes depend on relative wages, expected growth rates, etcetera (for more details see MASTER (1997)). Because entrepreneurs are by assumption distributed over those classes, aggregate employment must be obtained by aggregation over the corner-solutions belonging to each of the three classes of entrepreneurs, using the number of entrepreneurs in each class as weights. While this approach avoids bang-bang behaviour, the valuation of the present value of the costs associated with the relevant allocation sequences for each class becomes much more intricate. For a detailed description see MASTER (1997).

\section{The Estimation of the Model}

\section{Introduction}

In this section we present the estimation results for the model described in the previous section. Because of the relatively limited amount of data we had at our disposal, it proved to be necessary to simplify the overall substitution structure of the model to some extent : we specified the jobisoquant to be given by a Leontief structure, while leaving the rest of the model in tact. This implies that, measured in efficiency units, the job-composition of employment has been assumed to be more or less fixed, with the exception of the influence of exogenous trend terms.

It should be stressed here that the results used here are for illustrative purposes only, because more work is needed to extend the data-base in order to create the degrees of freedom necessary for sound empirical estimation of the parameters of the model. Despite the obvious shortcomings in this respect of both the data our empirical work so far, the results are interesting enough by itself to present them.

\section{Data and Classification Issues}

The data we have had at our disposal are from Eurostat. However, they cover only very few years. In fact, for Germany we have available employment and unemployment data for the years 1988-1991, while data for the Netherlands are available for a longer period, i.e. 1979-1989, due to additional data from the labour force surveys of the Netherlands Central Bureau of Statistics. An extensive overview of the data and the preliminary calculations we have performed on them is presented in MASTER (1997).

The employment data are available at a sectoral level for seven sectors with indices A, B, E, F, $\mathrm{M}, \mathrm{N}$ and T, respectively: A being the advanced sector, $\mathrm{B}$ the building and construction sector, $\mathrm{E}$ the energy sector, $\mathrm{F}$ the financial and other services sector, $\mathrm{M}$ the material services sector, $\mathrm{N}$ the non-market sector and $\mathrm{T}$ the traditional industries sector. For each worker we know the type of job she or he is working, with indices $A, P$ and $T$, respectively: A stands for administrative/commercial job, $\mathrm{P}$ stands for personal services and T represents technical jobs. Finally we also know the level of skill of each worker, where we distinguish three skill levels: low, medium and high. 
As regards the wage data, these are only available by sector and by skill-level. This is unfortunate, because it excludes the possibility to specify an alternative to the present model in which wages are paid in accordance with the job-level of the match under consideration rather than with the skill-level. ${ }^{17}$ Although one might regard this as a shortcoming of the model, one should consider that a change in perspective towards wages being paid by job-level rather than by skill-level necessarily refocuses the explanation of the skill-composition of employment on the supply of skills rather than the demand for skills. ${ }^{18}$ This is, however, not the approach taken in most macro-economic models, and it is also not the approach taken in the present paper.

\section{Classification Issues}

The analysis presented above, can easily be extended to more than two job-levels/job-types and skill-levels. Indeed, in the empirical implementation of the model for Germany and the Netherlands, we have actually distinguished between three job-levels (high, medium and low) as well as three different skill-levels (also high, medium and low) - with indices $\mathrm{H}, \mathrm{M}$ and L respectively. The naming of the job- and skill-levels suggests a one-to-one correspondence which is not supported by the data, i.e. one would expect jobs of a certain level to be filled predominantly by skills of the same level, while employment of skills with levels lower than the job-level would have to be ruled out on the basis of our a priori notions about substitution asymmetries. Again, this a priori notion is not supported by the data.

There are several reasons why such a one-to-one correspondence might be lacking. First of all, the educational classification covers only the level of education attained during normal schooling years: any additional learning/schooling is ruled out. This would provide a direct explanation of the possibility to observe matches between skills and jobs, where skill-levels apparently fall short of job-levels. Secondly, if both the job-classification and the skill-classification are obtained by aggregation over more detailed classifications which do have a one-to-one correspondence, the correspondence between skill-levels and job-levels may be broken when the classes over which job-levels and skill-levels are aggregated are not the same. Since we have only fairly aggregated data at our disposal in the first, we should not really expect to find a one-to-one correspondence. However, the unfortunate consequence is that the data we have at our disposal is not consistent with the model we have presented above.

In order to resolve this issue, we assume that when a person with a low skill-level is observed to be working in a job with a higher level, a wrong classification has been made. Hence, that person should be reclassified. The problem is that we do not know whether a mis-classification is due to an error at the job-side of the classification or at the skill-side. For the reclassification of the mis-classified person we assume that both errors are present in proportion with the relative

17) Although the approach we have taken here is consistent with the neo-classical idea that wages reflect the marginal productivity of workers and that the marginal productivity of a worker is higher, ceteris paribus, the higher his skill-level is, one could also consider situations where high-skilled workers on low-level jobs are paid lower wages than the same workers on high-level jobs.

18) A certain match between skills and jobs, and especially the employment of high skills on low jobs, depends explicitly on the willingness of the persons under consideration to be employed on those jobs. See also Heijke and Borghans (1996) and Robinson (1997). 
frequencies of the adjoining classes in the job-skill classification. ${ }^{19}$ This reclassification introduces a discrepancy between the 'official' data and the data which is consistent with the model - which is an unfortunate situation. However, by assuming that the number of people who are wrongly classified from the perspective of the model are a more or less constant fraction of the 'new' elements in the modified classification, we can 'deconstruct' the outcomes of our model by applying the reclassification procedure to the model outcomes in reverse. In the absense of more detailed information regarding effective skill-levels, this is obviously a second best solution to the problem of how to handle data inconsistencies, but a comparison of our results with the observed data remains possible in principle.

In addition to these manipulations and reclassifications, we have smoothed the employment figures and unemployment figures obtained in this way, because the changes over time in the distribution of the employment figures are fairly irregular. In fact, we have obtained the shares of employment and unemployment by skill-level and skill-type by means of a two-year moving average for the years from and including 1989. In order to obtain employment figures by skilllevel, skill-type and job-level and job-type, we have retrapolated the distributions of employment and unemployment from their 1988 values in the case of Germany. In case of the Netherlands, we have obtained figures for the years which are not covered by the CBS 'Enquete beroepsbevolking' data by means of straightforward linear interpolations of the distributions of employment and unemployment in both skill and job dimensions in the years adjoining the gaps in the data.

\section{Estimation Results}

Because of the linear programming nature of the matching process, it is not possible to use standard methods to estimates the various relative efficiency parameters and switching cost parameters from the data described above. Instead, we use a genetic estimation procedure which is based on Goldberg (1989). This genetic search algorithm encompasses the linear programming problem which was described in section 2 , and combines both data with respect to job-demand measured in (quasi-) efficiency units and sectoral supply constraints. The objective of this search algorithm is to find a parameter vector that minimizes an objective function. This objective function is defined as the sum of the squared residuals between generated optimum employment and observed employment by skill/job-type match. We also add a penalty to this sum when the calculated quasi-rate of labour utilisation falls below 1 . The procedure is described in detail in MASTER (1997).

19) In order to clarify the reclassification procedure, let $f_{j, s}$ represent the two-dimensional frequency distribution of skills over jobs, where $\mathrm{j}$ represents the job-level and $s$ the skill-level. If $f_{j, s}>0$ for some $s<j$ (where increases in $\mathrm{s}$ and $\mathrm{j}$ correspond with increases in skill- and job-levels), then a new frequency distribution $\mathrm{f}_{\mathrm{j}, \mathrm{s}}^{\mathrm{i}}$ is obtained by distributing the value $\mathrm{f}_{\mathrm{j}, \mathrm{s}}^{\mathrm{i}}$ over the adjoining elements $\mathrm{f}_{\mathrm{j}-1, \mathrm{~s}}^{\mathrm{i}}$ and $\mathrm{f}_{\mathrm{j}, s+1}^{\mathrm{i}}$, in proportion with the values of these elements. i denotes a stage in the distribution process. The process continues until all 'wrong' elements have disappeared. With respect to the employment of high-skilled workers on low-level jobs, we assume that the observation is due to a mismeasurement of the job-level. Consequently, we reclassify this entry as high-skilled workers on a medium level job. 


\section{Estimation Results for Germany and the Netherlands}

For both Germany and the Netherlands the estimated relative efficiencies are relatively close to 1.25 as is shown in Figure 4. A notable exception is the relative efficiency of medium skilled workers in low-level jobs for the German E-sector, which appears to be about 1.6 for all three job types. This reflects the exceptionally high relative wages for medium-skilled workers vis a vis low-skilled workers in the E-sector (also roughly 1.6). For the Netherlands, the relative efficiency of high-skilled workers in medium-level jobs is relative high for all three job types in the M-sector whereas the relative efficiency of the high-skilled workers in medium-level jobs is very low for the personal jobs in the T-sector. Moreover, the relative efficiencies are more equal for Germany than for the Netherlands. In general, however, the relative efficiencies are roughly equal to relative wage rates - both for high skills relative to medium skills and medium skills relative to low skills. Because we have transformed job-demand measured in man-years into jobdemand measured in efficiency units by using relative wages by skill as a relative efficiency indicator, this is what one could more or less expect. However, the class sizes of different switching classes depend on relative wages and efficiencies too. Hence there are other influences of relative wages on the estimation results beside the ones through the job-demand constraint and the valuation of the present value of the costs of the various allocation sequences.

Another remarkable result is that the learning costs as a fraction of the wage costs by skill are very different for different sectors and different job types. ${ }^{20}$ The estimated upper bounds ${ }^{21}$ on these learning cost parameters are presented in Figure 5 for both countries. One can roughly conclude that there is a tendency for learning costs to be relatively low for low-skilled workers for all sectors in the $\mathrm{P}$ jobs, and for most $\mathrm{T}$ jobs. ${ }^{22}$ This indicates that apparently, given changes in relative wage rates, supply conditions and so on, the skills needed to perform satisfactorily on low-level technical jobs in the German advanced sector A and the building and construction sector B and in the Dutch Energy sector E and Financial services sector F are more difficult to acquire than the skills necessary for low-level technical jobs in other sectors. For the other sectors one can roughly conclude that as far as technical jobs are concerned, the costs of acquiring the skills necessary for medium-level jobs are often more outspoken than the costs of acquiring the skills necessary for low-level jobs and for high-level jobs. Although this may seem to be hard to understand at first, it may indicate that especially the medium-level jobs determine the sector specificity of the jobs in question, where low-level jobs only need 'eye hand coordination' in the words of Romer (1990), while high-level jobs require the execution of functions which are less sector specific, like management, computer engineering, and so on. This conclusion also holds for administrative jobs, with the exception of the $\mathrm{M}$ and $\mathrm{N}$ sector, for medium-level and high-

20) A word of warning is necessary here, since the administrative job-type does not have any positive employment entries in the low-level administrative jobs, both for Germany and the Netherlands. This means that the job-demand constraint in combination with a positive present value price of an allocation to such a low-level administrative job, forces the estimated employment entries to be equal to zero for any value of relative efficiencies and relative wages. Consequently, one should disregard the results obtained for low-skilled administrative jobs.

21) As one may recall, we assume entrepreneurs to be uniformly distributed over these learning costs parameters between a zero lower bound and the estimated upperbounds presented here.

22) The exception is T-jobs in the A and B sectors for Germany and in the E and F sectors for the Netherlands. 
level administrative jobs. ${ }^{23}$

As regards the asymmetries in learning costs for higher-skilled persons on job-levels below their skill-levels, there is again a fairly wide dispersion in the results. This can be seen from the results for the parameter phi, which represents the fraction by which the learning costs of mediumskilled workers on medium-level jobs should be multiplied to obtain the learning costs of the medium-skilled workers on low-level jobs. The same fraction is used for high-skilled workers on medium-level jobs. The results show that for the Netherlands, the learning costs for these workers are not that different from the learning costs of the medium-skilled workers on mediumlevel jobs and high-skilled workers on high-level jobs. For Germany, the results are different where, for instance, the learning costs of high- and medium-skilled workers on medium- and low-level jobs are almost zero in the $\mathrm{M}$ and $\mathrm{N}$ sector.

In general we may conclude that the estimates are roughly as expected. First, the relative efficiencies seem to be much more reliable than the learning cost parameters. This is only natural, since we have much more direct information about relative efficiencies (in the form of relative wages) than for the other parameters. In addition to this, the estimation period is very short, while at the same time only a limited number of estimation runs has been performed, due to the timeconsuming nature of the estimation process. Nonetheless, the results we have obtained so far, seem to indicate that learning costs are an important determinant of the matches between skills and jobs, since a zero value of all learning parameters is included in the permissible range of variation of the parameters under consideration.

23) Note that in the case of administrative jobs, we may disregard the estimates for low-level jobs. See also the previous note. 
Figure 4. Parameter estimates of the relative efficiencies.

Germany
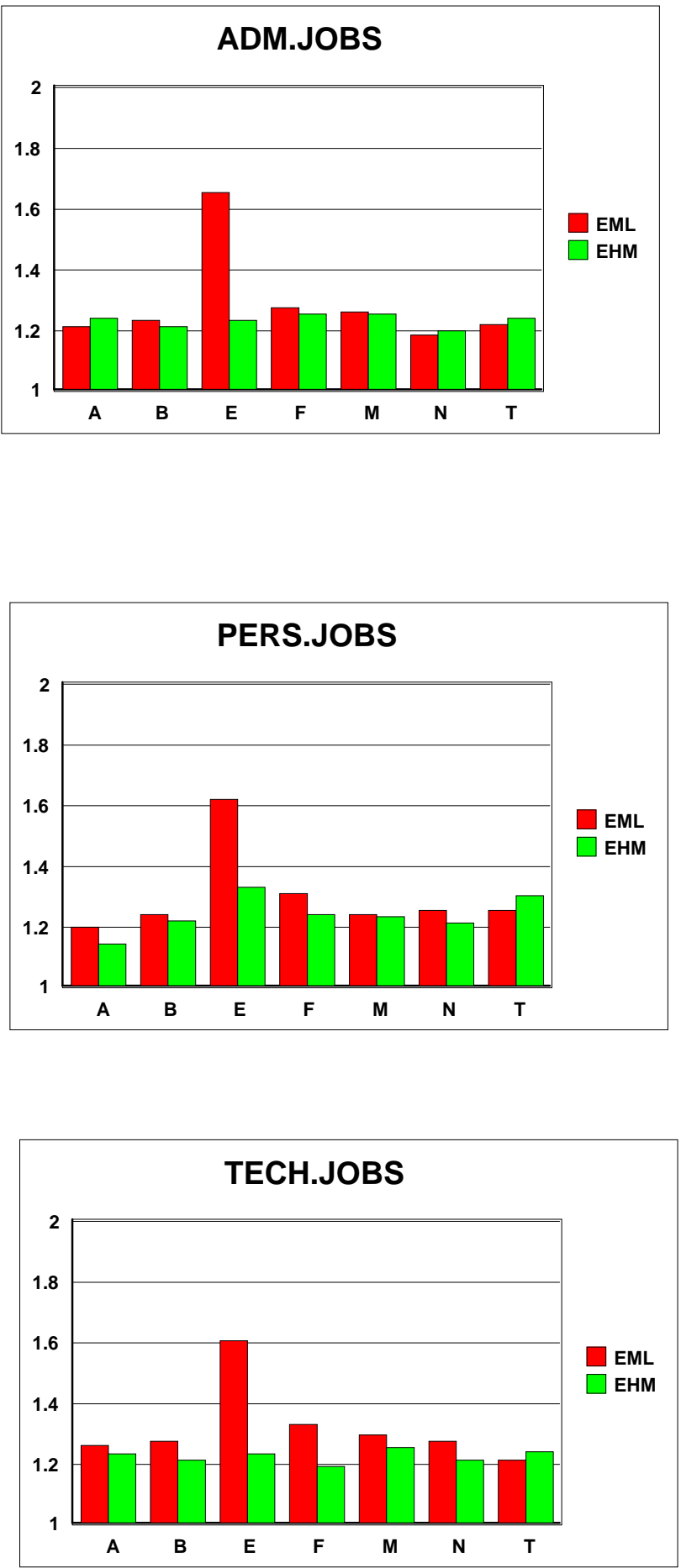

The Netherlands
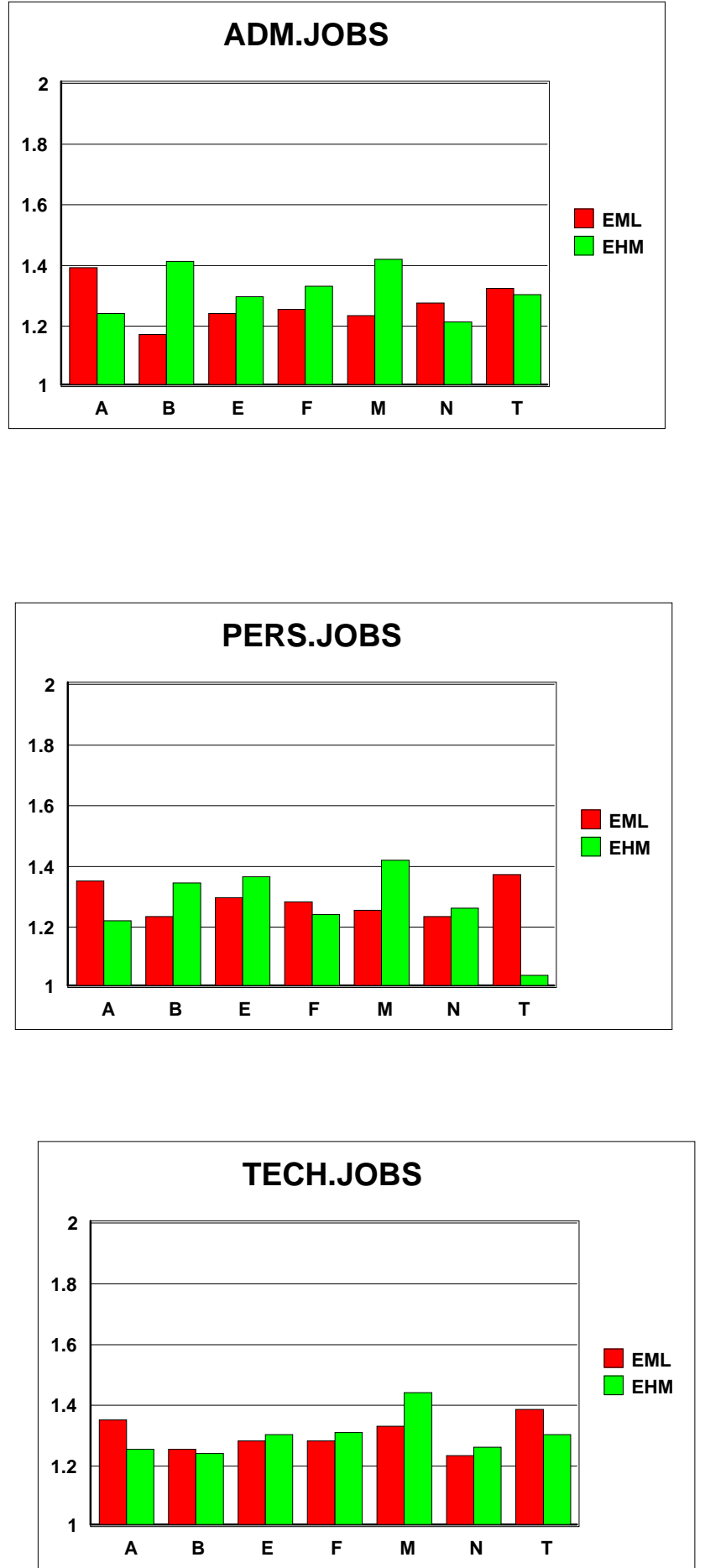
Figure 5 Parameter estimates of the learning costs $\left(\xi_{L, L}, \xi_{M, M}, \xi_{H, H}\right.$ and $\left.\phi\right)$

Germany
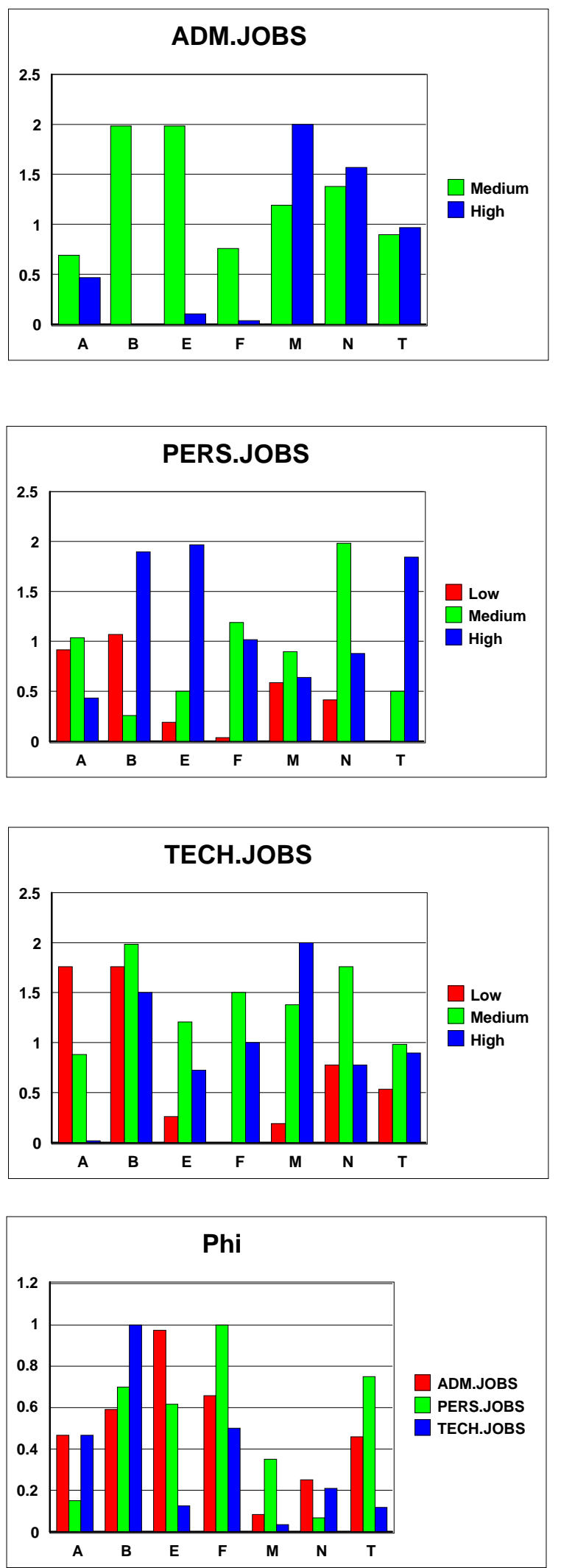

The Netherlands
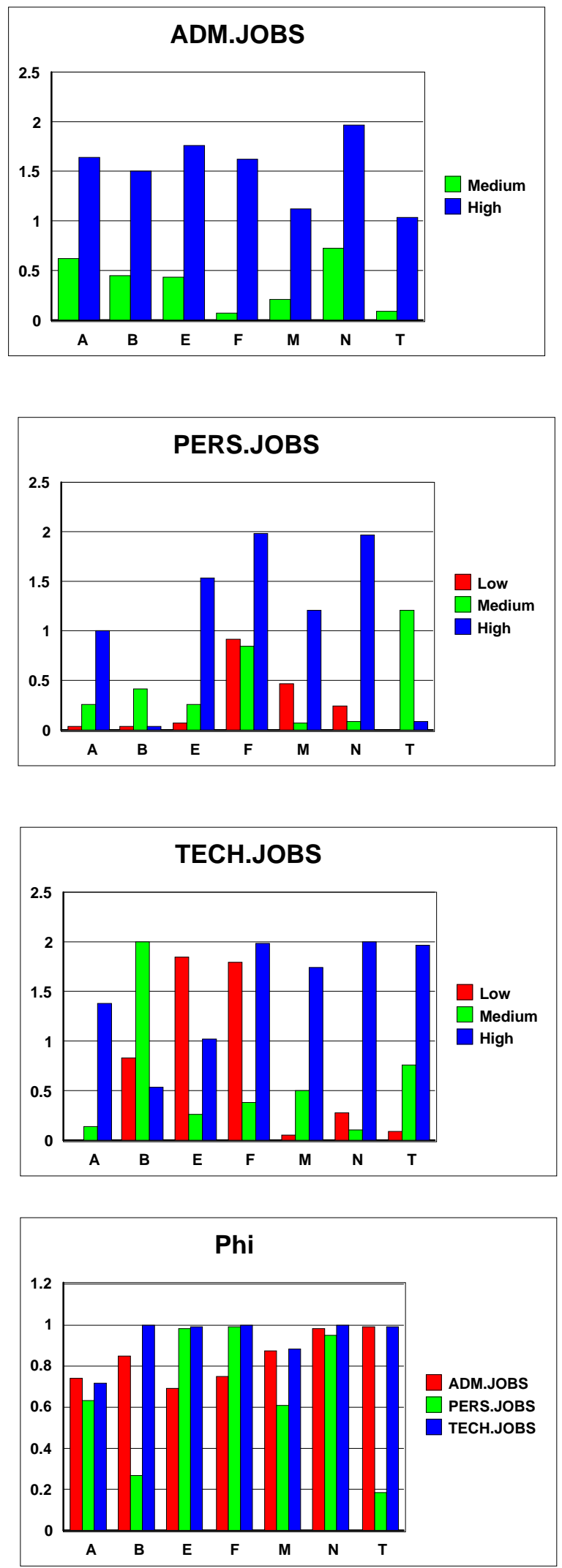


\section{Some Simulation Experiments}

The model described in section 2 has been used to perform two ex post simulation experiments for Germany and the Netherlands. These experiments are meant to illustrate the influence of the chimney-effect on employment and to emphasize some interactions which might be relevant from a policy point of view. It should be stressed here that these are stand-alone experiments: the simulation results obtained here do not reflect induced substitution effects between labour and capital (those between jobs have been ruled out already due to the Leontief structure we have had to impose). Such effects would obscure the illustration of the working of the chimney effect, which is the subject of this paper. Nonetheless, it should be stressed here that those induced substitution effects may alter the results, depending on the nature of the experiment. Where relevant, we will indicate how the results would be influenced by those induced susbtitution effects. So in the simulation experiments the total demand of labour in terms of efficiencies is given.

The first experiments we have performed are concerned with the creation of low-, medium- and high-level jobs for all job-types we have distinguished. As one will recall from section 2 , we have specified a Leontief job-demand structure, measured in efficiency units, where the shares of the job-types in total employment are constant (apart from an exogenous linear trend term) and where the shares of job-levels in the various job-types are constant too (again apart from a linear trend-term). This means that the job demand $J_{t, 1}$ can be written as: $J_{t, 1}=a_{t, 1} \cdot b_{t} \cdot E$, where the subscript $t$ denotes the job type, and 1 denotes the job level. $a_{t, 1}$ denotes the share of job-type $t$ and level 1 in total jobs of type $t$, while $b_{t}$ denotes the share of all jobs of type $t$ in total job demand $\mathrm{E}$, all measured in efficiency units. Note that we have dropped the sectoral dimension here for ease of exposition. The experiment we have conducted pertains to an increase in $\mathrm{a}_{t, 1}$ by 0.01 , for each of the different job levels. ${ }^{24}$ The first experiment is concerned with an increase in all lowlevel jobs, the second with all high-level jobs and the third with all medium level jobs. Note that the replacement of $\mathrm{a}_{\mathrm{t}, 1}$ by $\mathrm{a}_{\mathrm{t}, \mathrm{l}}+0.01$ increases $\mathrm{J}_{\mathrm{t}, \mathrm{l}}$ by the same absolute amount in all cases, i.e. by $0.01{ }^{*} b_{t}$.E. Hence, if the additional jobs would be manned by people with the same skill-level as the job-level under consideration, employment of a particular type would increase by the same number of people. Obviously, the latter does not have to be the case, since higher skilled people may take the jobs of lower skilled people, depending on the situation on the various (skill-) labour markets. With regard to induced substitution effects, it should be noted that this experiment increases, ceteris paribus, effective labour costs per unit of output. Consequently, a decrease in the labour/capital ratio would be expected, thus decreasing the original expansion of jobs somewhat. This would still leave an absolute increase in the number of jobs which had expanded in the first place, but it would also lead to an absolute decrease in the demand for other jobs.

A second experiment is concerned with a reduction in the wage costs of low-skilled workers, by means of a 15 percent subsidy on wage costs. While this may seem to be a large amount, this will only lead to modest changes in the total wage sum by sector of industry and hence to modest induced substitution effects between labour and capital. This is due to the fact that the share of

24) Note that this increase by 1 percentage point in $\mathrm{a}_{\mathrm{t}, \mathrm{l}}$ is not matched by an average decrease of 1 percentage point elsewhere, so that the interpretation of $\mathrm{a}_{\mathrm{t}}$ as an employment share is actually violated. The 0.01 increase in $\mathrm{a}_{\mathrm{t}, \mathrm{l}}$ therefore represents a net increase in the corresponding skill-intensity of labour demand. 
the low-skilled in total employment is fairly low, as opposed to their share in unemployment.

\section{Simulation Results for Germany}

The results of the experiment in which we have increased the number of low-skilled jobs as described above, are summarised in Figures 6 and 8. This can be compared to the results when we increase the number of all high-level jobs instead - cf. Figures 7 and 9. In all Figures a reference run is presented too. This is the dotted line: it shows the outcome of the model when the estimated parameter values are used. As is discussed in MASTER (1997), the reference run generally shows a very close fit to the observed data. ${ }^{25}$ From Figure 6 we see that, due to the increase in low-level jobs, the rate of unemployment falls by about 0.7 percentage points. However, in the case of an increase in the number of high-level jobs, the drop in the overall rate of unemployment is of the order of 1 percent, as can be seen from Figure 7.

The reason for this asymmetry in the results can be understood when the underlying changes in employment are studied in more detail. The increase in the number of low-level jobs does not affect employment of high-skilled workers (see Figure 8a), while employment of both low-skilled workers and medium-skilled workers are positively affected. In fact, the increase in employment for medium-skilled workers is much larger than for low-skilled workers. This points to two things. First of all, there are many more medium-skilled workers occupying a low-level job than there are low-skilled workers doing that. Secondly, although low-level jobs are created in this experiment, this is primarily beneficial for medium-skilled workers. ${ }^{26}$

Figure 6 Unemployment Change due to an increase in low-level jobs

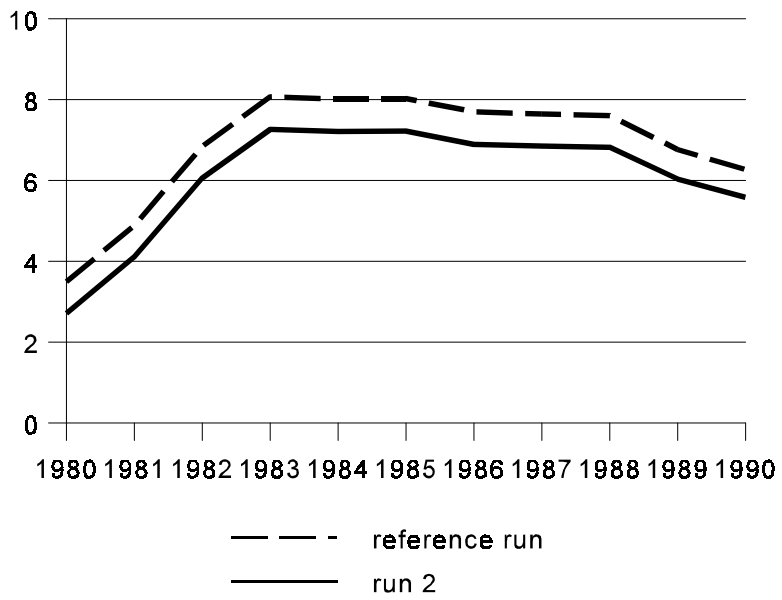

Figure 7 Unemployment Change due to an increase in high-level jobs

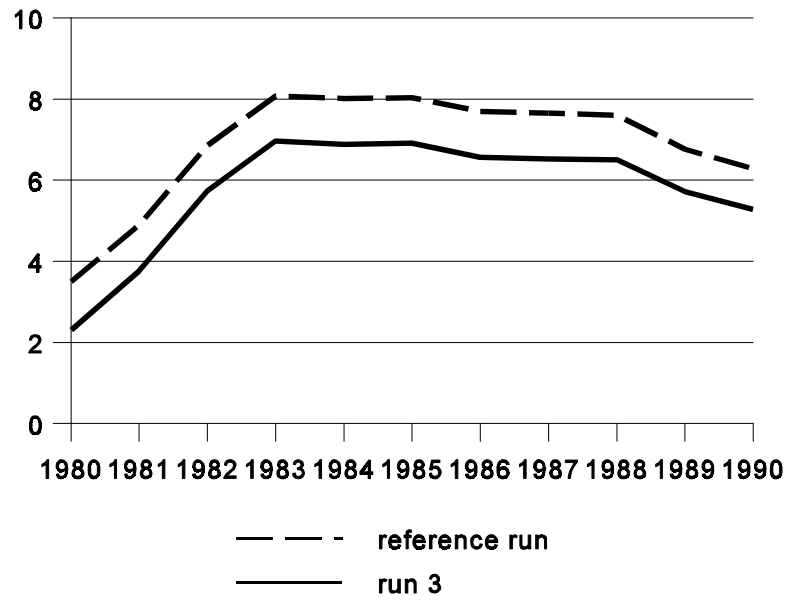

25) Thare are a few exceptions to this rule, however. For example, the drop in low-skilled employment in 1982 as shown in Figure 8c is due to a relatively bad performance of the model in those years. This drop is not in the data themselves. But because the employment share of low-skilled workers is so low, such a drop can be compensated within the model by only a relatively minor increase in employment of medium-skilled workers, which is indeed what happens.

26) It should be stressed here that our conclusion may be exaggerated because of the transformations on the data we have had to perform in order to make them compatible with our model. 
When we increase the number of high-level jobs we see that, contrary to the previous experiment, employment of high-skilled workers is now positively affected, although still fairly little (Figure 9a). Moreover, the increase in employment of the low-skilled is far higher than the corresponding increase in employment of the high-skilled (Figure 9c), especially in the beginning of the experimental period. A similar change occurs to employment of medium-skilled workers - cf. Figure $9 \mathrm{~b}$. The conclusion is that we see here an example of the chimney effect at work. Total employment of high-skilled workers can not change much, because unemployment of highskilled workers is relatively low already. Hence, the additional high-level jobs need to be filled using high-skilled workers previously employed on medium-level jobs. The vacant medium-level jobs in turn are filled using medium-skilled workers, who need to be drawn in part from the pool of unemployed, but also from low-level jobs. Hence, here we see an example of the creation of high-level jobs having a beneficial effect on low-skilled employment. However, medium-skilled workers profit most. This is only natural, since these are the ones who are first in line to fill the employment gaps left by high-skilled workers moving into high-level jobs, while the low-skilled workers are only second in line if there are suplly shortages of medium-skilled workers.

We do not present the outcomes of the experiment in which we increased the number of medium level jobs. In MASTER (1997) we explain that this raises both the employment of low-skilled and of the medium-skilled workers, because the pool of unemployed medium-skilled workers is not enough by itself to supply the extra amount of labour needed to fill the additional mediumlevel jobs. And although high-skilled workers could be used to fill medium-level jobs, this does not happen, because high-skilled workers are already in relatively short supply.

Figures 10 and 11 contain the results of a 15 percent subsidy on wage costs for all low-skilled workers. Since total employment measured in efficiency units is fixed by assumption (because of the stand-alone character of the experiments), this means that we should expect low-skilled workers to be hired for low-level jobs more frequently than before. However, they would replace medium-skilled workers who were employed in low-level jobs, hence the net effect on total employment should be of very limited size. But even though employment in efficiency units is fixed a priori, this is not necessarily the case with employment measured in physical units, because one medium-skilled worker can replace roughly 1.25 low-skilled workers, while one high-skilled worker replaces about 1.25 medium-skilled workers, as shown by the estimates of the relative efficiencies in section $3 .^{27}$ This implies that a reshuffling of employment for a given job-type, can still have net positive effects, even though employment in efficiency units is constant. This is actually what is shown in Figure 10, which shows a drop in the aggregate rate of unemployment due to the subsidy. The subsidy favours the employment of low-skilled workers on low-level jobs, which makes the previously employed medium-skilled workers more or less redundant. They enter the labour market, and some of them succeed in driving out the highskilled workers which took up medium-level jobs, due to the existence of previously binding constraints with respect to the supply of medium-skilled workers. We see then that a subsidy on the employment of low-skilled workers does indeed lead to positive employment effects at the aggregate level, although medium-skilled employment and even high-skilled employment fall.

27) Note that this implies that we essentially have a low-skilled employment creation multiplier which is associated with the creation of one high-level job with a maximum value of about 1.55 which would be realised when this high-level job is filled by a high-skilled worker previously occupying a medium-level job, which then is taken by a medium-skilled worker who previously occupied a low-level job. 
Figure 8 An increase in low-level jobs

Figure 8a High-skilled employment

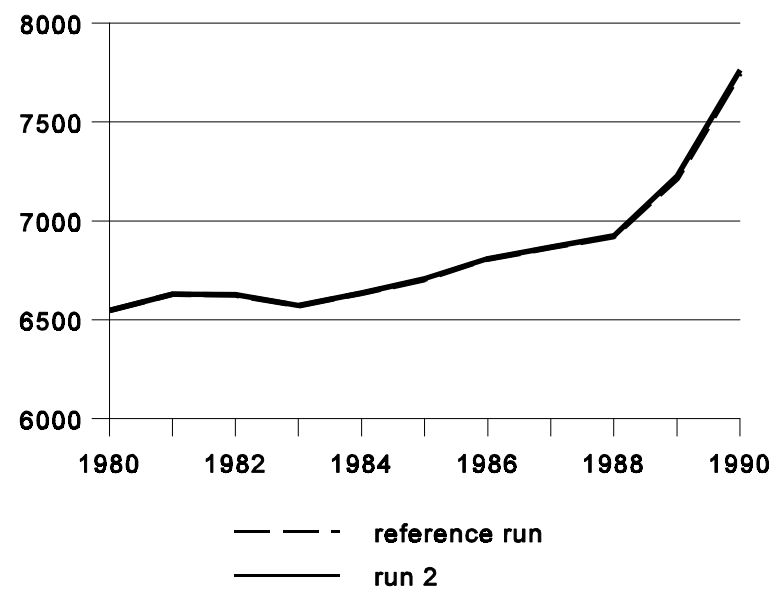

Figure 8b Medium-skilled employment

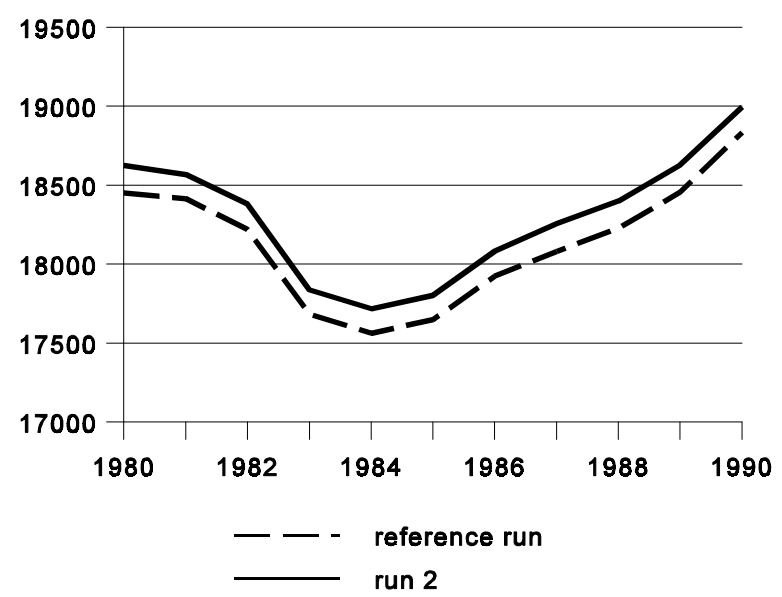

Figure 8c Low-skilled employment

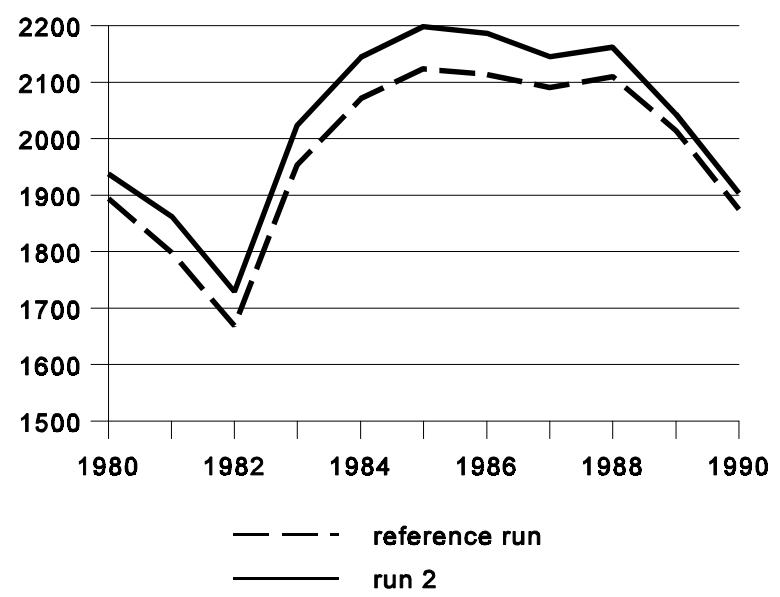

Figure 9 An increase in high-level jobs

Figure 9a High-skilled employment

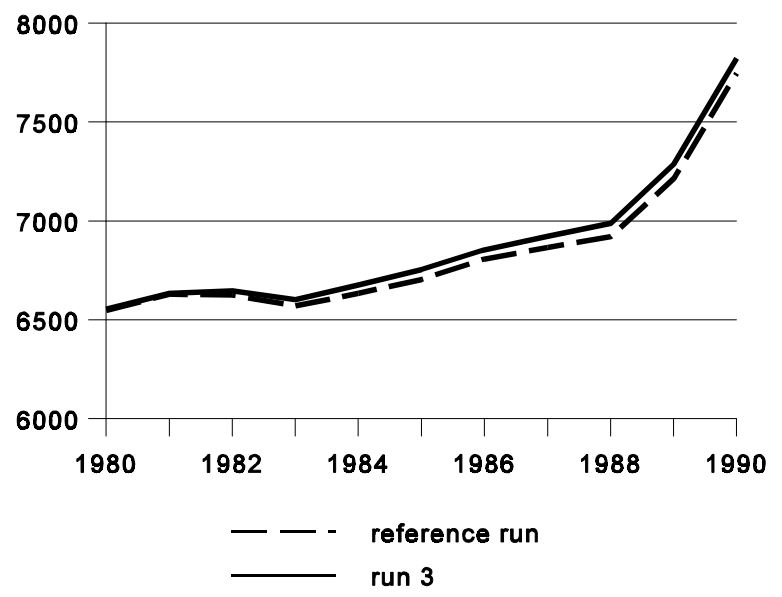

Figure 9b Medium-skilled employment

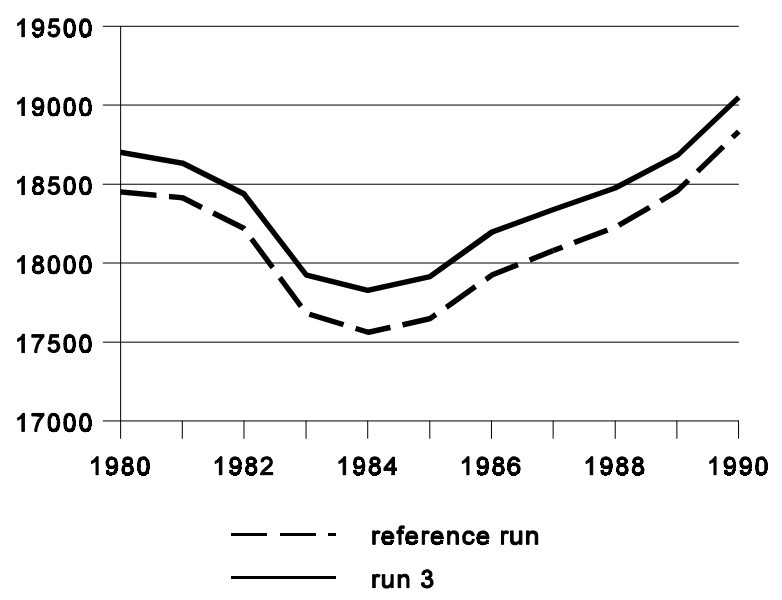

Figure 9c Low-skilled employment

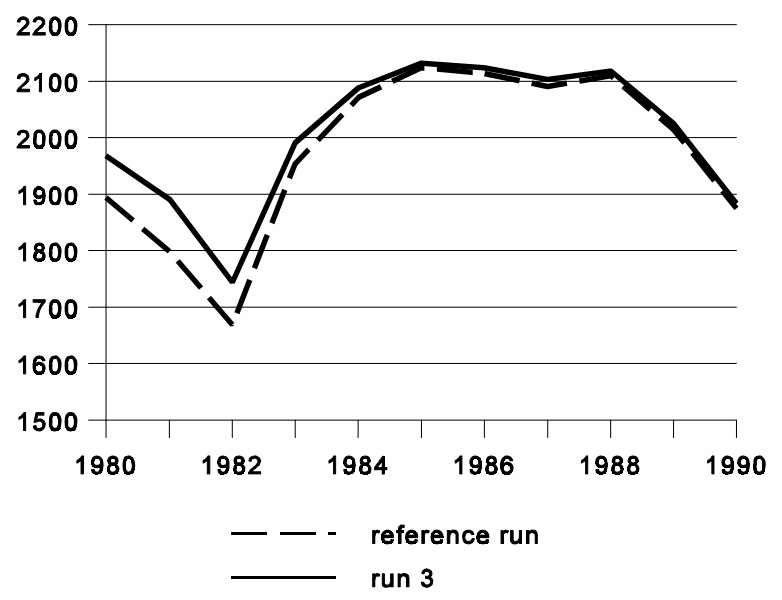


Figure 10 Unemployment change due to a decrease in low-skilled wage costs

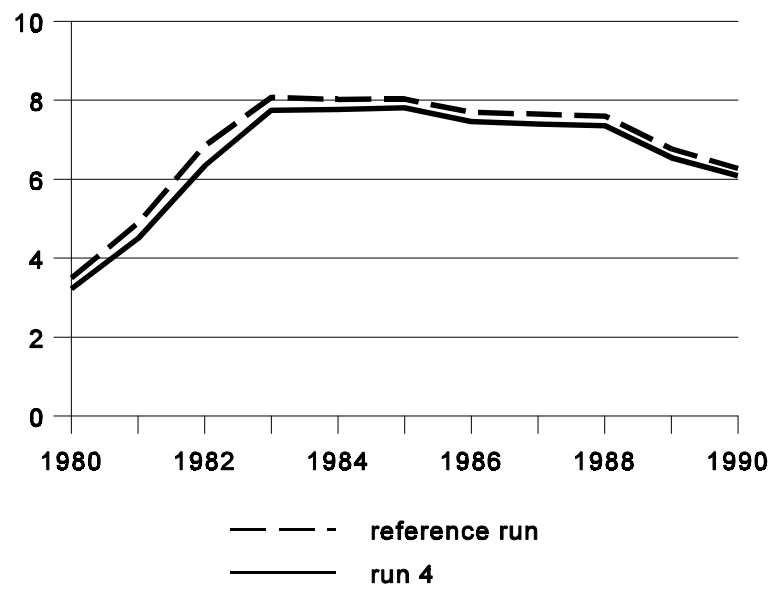

Figure 11b Employment of medium-skilled workers

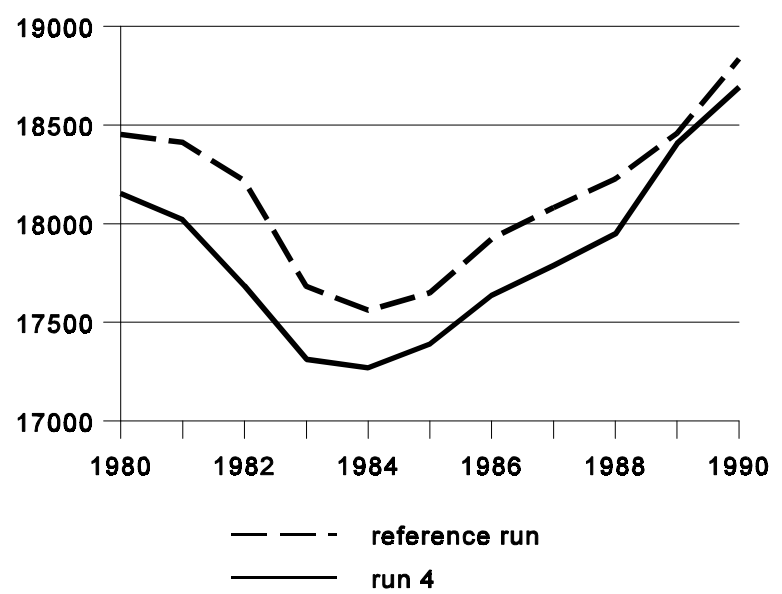

Figure 11a Employment of high-skilled workers

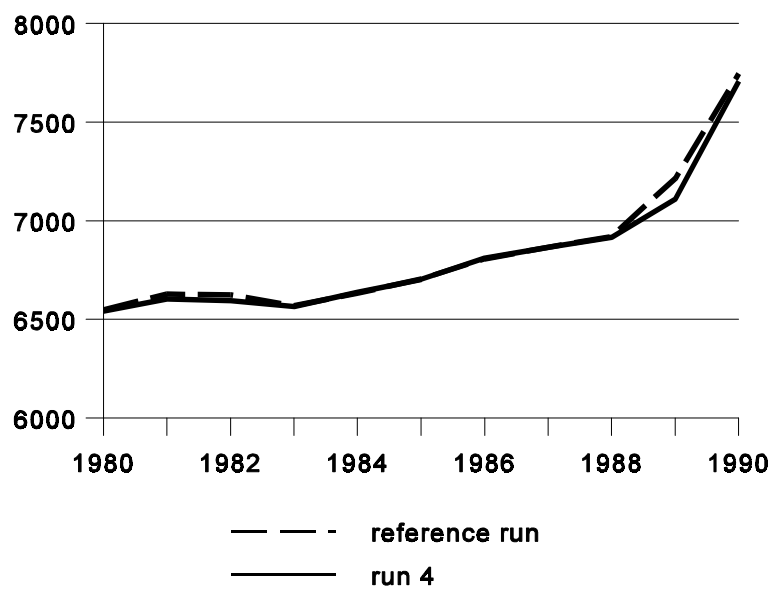

Figure 11c Employment of low-skilled workers

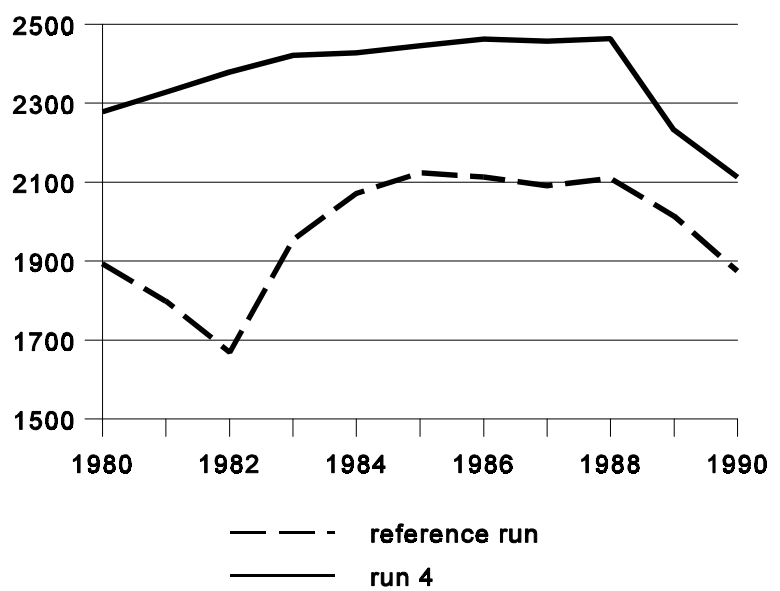

\section{Results for the Netherlands}

For the Netherlands we have performed the same experiments as for Germany. We will not present them in detail, but refer to MASTER (1997) instead. The results are very similar as far as the ones for the increase in low-skilled jobs are concerned. But the results for the increase in high-skilled jobs are very different, because the rate of unemployment rises at first, which may seem to be somewhat odd. The reason is that an increase in the high-level job intensity of labour demand for a given supply of high-skilled workers may actually lead to a quantitative shortage of the supply of high-skilled workers, which, by assumption, are the only ones which can take those high-level jobs. Since high-skilled workers were already in short supply, the supply constraints become even so binding that total demand for high-level jobs can not be filled for the given sectoral distribution of high-skilled workers. Consequently, due to the Leontief character of the job structure of employment, the demand for low- and medium-level jobs is negatively 
affected too (there is no use in hiring low- and medium-skilled workers, when the functions which high-skilled workers should perform can not be executed because of a quantitative shortage of the supply of high-skilled workers). Only when job-to-job movements help to alleviate these quantitative supply shortages, the aggregate rate of unemployment drops below the base-run value.

In the experiment with a 15 percent subsidy on low-skilled wage costs, we see a very minor net positive effect on unemployment. This indicates that supply constraints on medium-skilled workers are more binding in the Netherlands than in Germany, i.e. even though the relative efficiency estimates are of the same order of magnitude in both Germany and the Netherlands, the substitution effects ex post are more limited due to the existence of supply constraints.

\section{Summary and Conclusion}

In this paper we have presented a model of the allocation of labour of three different skill-levels (low, medium and high) to jobs which require certain minimum skill-levels (also low, medium and high). This means that low-skilled people can not perform in medium- and high- level jobs, while medium-skilled people can take both medium-level and low-level jobs. High-skilled people could perform well in medium- and high-level jobs. We furthermore assumed that people with a certain skill-level may perform more efficiently on certain jobs than people with a skill-level which exactly matches the job-level. This means that from a demand point of view a match between skills and jobs depends on relative wage-costs by skill. Consequently, mismatches refer to non-costminimising matches between job- and skill-levels rather than to direct differences between job-levels and the skill-levels of the people associated with those jobs. Additional asymmetries between skills are introduced with respect to learning abilities, which favour the employment of groups with relatively low learning costs. These asymmetries between skills are important, because it stresses the fact that a match on the labour market will only take place when the person in question has the ability to (learn to) perform satisfactorily in a certain job. Consequently, reductions in wage costs only increase the relative demand for certain skills for certain jobs if the skills in question are suited for those jobs: reductions in wage costs alone are not sufficient to further employment of certain skill groups.

Apart from the demand for skills which follows from the job-compostition of labour demand, we have integrated the supply of skills in a linear programming framework. Thus we are able to show how the creation of high-level jobs can improve the employment prospects of low-skilled people by reducing the displacement of low-skilled people by medium-skilled people on lowlevel jobs. The mechanism present in the model sees to it that the increase in the demand for high-skilled people caused by an increase in high-level job demand (due to our assumptions regarding allocation asymmetries, high-skilled workers are the only ones who can take on highlevel jobs) shifts high-skilled workers out of medium-level jobs, medium-skilled workers into medium-level jobs and out of low-level jobs, while low-skilled workers can move into the jobpositions freed by medium-skilled workers. We have seen this mechanism at work in a number of experiments we have conducted for Germany and the Netherlands.

In the experiments for Germany in particular we have seen the chimney effect at work. We saw that the creation of high-level jobs may lead to the employment of medium-skilled workers and low-skilled workers in job-openings which arise due to job-to-job movements of high-skilled workers from medium-level jobs to high-level jobs. We also saw that a subsidy on low-skilled wages, even when labour demand in efficiency units was constant, may actually raise the level 
of total employment, due to the fact that medium-skilled workers are driven out of low-level jobs, where those workers took the place of 1.25 low-skilled workers on average. This implies that the full employment multiplier associated with the creation of a high-level job may be as high as 1.55 , i.e. 1.55 people may find work due to the creation of one high-level job. By contrast, the creation of 1 additional low-level job will lead to additional employment of at most 1 worker.

In the experiments for the Netherlands we saw that the creation of high-level jobs may actually cause the occurrence of unemployment for medium- and low-skilled workers instead of generating positive employment effects as it did in the case of Germany. The reason is that the logic of the model allows supply constraints of high-skilled workers to become that binding, that total job demand can not be fulfilled within the limits set by the supply constraints, and, given the Leontief structure of job demand which we have postulated, the demand for medium- and low-level jobs is negatively affected too. This stresses the point that the creation of high-level jobs is not a panacea for low-skilled unemployment problems. Rather, its effectiveness in this respect depends on high-skilled workers being in relatively high demand, but not too high at the same time, so as to avoid the negative impact on overall job-demand of an 'absolute' excess demand for high-skilled workers. ${ }^{28}$

In general then we conclude that the experiments we have conducted with the model underline the relevance of both the chimney effect and the trickle down effect, as well as the importance of displacement in determining overall employment opportunities for the various skills under consideration. The experiments also show how asymmetries in substitution possibilities may actually lead to job creation multiplication effects which, however, depend very much on the existence of qualitative binding supply constraints in the higher skill echelons and the simultaneous absence of binding quantitative supply constraints in these same echelons.

28) Note that the ensuing increase in high-skilled wages would lead to substitution of capital for labour and to substitution of medium-skilled workers for high-skilled workers on medium-level jobs. This would mitigate the pressures of excess demand for high-skilled workers to some extent, thus reducing the negative impact of excess demand for high-skilled workers on the development of overall employment. 


\section{References}

Beer, P. d. (1996). "Laag opgeleiden: minder kans op een baan, meer kans op ontslag." Economisch Statistische Berichten: 908-12.

Broer, D.P. and W.J. Jansen, 1989, 'Employment, Schooling and Productivity Growth, De Economist, Nr. 137, pp. 425-453.

Drèze, J.H. and E. Malinvaud, 1993, Growth and Employment, the Scope of European Initiative, mimeo, CORE/College de France, Louvain-la-Neuve/Paris.

Gelderblom, A., J. d. Koning, et al. (1997). "Loont Studeren?" Economisch Statistische Berichten: 500-4.

Goldberg, D.E., 1989, Genetic Algorithms in Search, Optimization, and Machine Learning, Addison-Wesley, Massachusets.

Groot, W. and H. Maassen van den Brink (1996). "Overscholing en verdrininging op de arbeidsmarkt.” Economisch Statistische Berichten: 74 - 7.

Hamermesh, D.S. and J.H. Grant, 1979, 'Econometric Studies of Labor-Labor Substitution and Their Implications for Policy', Journal of Human Resources, 14, pp. 518-542.

Hebbink, G.E., 1991, 'Employment by Level of Education and Production Factor Substitutability', De Economist, 139, pp. 379-401.

Borghans, L. and H. Heijke (1996). Flexibility and the structure of the Dutch labour market. ROA10, Maastricht.

Kettunen, J. (1994). "The Effects of Education on the Duration of Unemployment." Labour 8(2): $331-52$.

Kugler, P., U. Muller and G. Sheldon, 1990, 'The Labor Market Effects of New Technologies an Econometric Study for the Federal Republic of Germany', in Schettkat, R. and M. Wagner (Eds.), Technological Change and Employment Innovation in the German Economy.

Laan, L. v. d. (1996). Substitution in the regional labour markets in the Netherlands. Utrecht/Rotterdam, KNAG/Faculty of Geographical Sciences Utrecht/Economic Geographical Institute Rotterdam.

MASTER, 1997, Final Report to the Commission of the EC, MERIT, Maastricht.

Muysken, J. and B. Ter Weel (1997). Does overeducation reduce unemployment? Maastricht, Maastricht University.

OECD, 1994, The OECD Jobs Study: Evidence and Explanations, Paris. 
Oosterbeek, H. and D. Webbink (1996). "Over scholing, overscholing en inkomen.” Economisch Statistische Berichten: 240-41.

Robinson, P. a. M. M. (1997), Qualifications and the labour market in Britain: skill biased change in the demand for labour or credentialism?, CEPR discussion paper 330, CEPR, London.

Romer, P., 1990, 'Endogenous Technological Change', Journal of Political Economy, pp. 71-102.

Van Ours, J. C. and G. Ridder (1995). "Job Matching and Job Competition: Are Lower Educated Workers at the Back of Job Queues?" European Economic Review 39(9): 1717-31.

Zon, A. van and J. Muysken, 1992, Matching Skill Supply and Demand: A Linear Programming Approach, MERIT Research Memorandum, 92-005.

Zon, A.H. van and J. Muysken, 1996, 'MASS: A model of Asymmetric Skill Substitution', MERIT Research Memorandum, 2/96-016. 